\title{
Imprint of Southern Ocean mesoscale eddies on chlorophyll
}

\author{
Ivy Frenger ${ }^{1,2,3}$, Matthias Münnich ${ }^{2}$, and Nicolas Gruber ${ }^{2,4}$ \\ ${ }^{1}$ GEOMAR Helmholtz Centre for Ocean Research Kiel, Kiel, 24105, Germany \\ ${ }^{2}$ ETH Zurich, Environmental Physics, Institute of Biogeochemistry and Pollutant Dynamics, Zurich, 8092, Switzerland \\ ${ }^{3}$ Princeton University, Program in Atmospheric and Oceanic Sciences, Princeton, 08544, USA \\ ${ }^{4}$ ETH Zurich, Center for Climate Systems Modeling, Zurich, 8092, Switzerland
}

Correspondence: Ivy Frenger (ifrenger@geomar.de)

Received: 6 February 2018 - Discussion started: 16 February 2018

Revised: 14 June 2018 - Accepted: 5 July 2018 - Published: 13 August 2018

\begin{abstract}
Although mesoscale ocean eddies are ubiquitous in the Southern Ocean, their average regional and seasonal association with phytoplankton has not been quantified systematically yet. To this end, we identify over 100000 mesoscale eddies with diameters of $50 \mathrm{~km}$ and more in the Southern Ocean and determine the associated phytoplankton biomass anomalies using satellite-based chlorophyll- $a(\mathrm{Chl})$ as a proxy. The mean $\mathrm{Chl}$ anomalies, $\delta \mathrm{Chl}$, associated with these eddies, comprising the upper echelon of the oceanic mesoscale, exceed $\pm 10 \%$ over wide regions. The structure of these anomalies is largely zonal, with cyclonic, thermocline lifted, eddies having positive anomalies in the subtropical waters north of the Antarctic Circumpolar Current (ACC) and negative anomalies along its main flow path. The pattern is similar, but reversed for anticyclonic, thermocline deepened eddies. The seasonality of $\delta \mathrm{Chl}$ is weak in subtropical waters, but pronounced along the ACC, featuring a seasonal sign switch. The spatial structure and seasonality of the mesoscale $\delta \mathrm{Chl}$ can be explained largely by lateral advection, especially local eddy-stirring. A prominent exception is the ACC region in winter, where $\delta \mathrm{Chl}$ is consistent with a modulation of phytoplankton light exposure caused by an eddyinduced modification of the mixed layer depth. The clear impact of mesoscale eddies on phytoplankton may implicate a downstream effect on Southern Ocean biogeochemical properties, such as mode water nutrient contents.
\end{abstract}

\section{Introduction}

Phytoplankton account for roughly half of global primary production (Field et al., 1998). They form the base of the oceanic food web (Pomeroy, 1974, e.g.,) and drive the ocean's biological pump, i.e., one of the Earth's largest biogeochemical cycles, with major implications for atmospheric $\mathrm{CO}_{2}$ and climate (Sarmiento and Gruber, 2006; Falkowski, 2012). Yet, our understanding of the processes controlling their spatio-temporal variations is limited, particularly at the oceanic submesoscale to mesoscale, that is at scales of the order of 0.1 to $100 \mathrm{~km}$ (e.g., reviews by Lévy, 2008; Mahadevan, 2016; McGillicuddy Jr., 2016). In this study we focus on mesoscale eddies, that is vortices with diameters of $50 \mathrm{~km}$ or more, and thus leave out the submesoscale variations. This choice is largely driven by the spatial resolution of the data we employ, but it is also motivated by the fact that mesoscale eddies have been shown to dominate the ocean's kinetic energy spectrum (Stammer, 1997; Chelton et al., 2011b), and affect phytoplankton in a major way (Lévy, 2008; McGillicuddy Jr., 2016). In comparison, the contribution of submesoscale processes to the variance in kinetic energy is smaller, and its role for phytoplankton variability, although potentially large (Mahadevan, 2016) is not well characterized. In contrast, mesoscale eddies have been recognized to be among the most important drivers for the spatio-temporal variance of phytoplankton (e.g., Doney et al., 2003; Glover et al., 2018), as has been noted already from the analyses of some of the very first ocean color satellite images of chlorophyll (Chl), a proxy for phytoplankton biomass (Gower et al., 1980). Despite decades of work since this discovery, the mechanisms governing the interaction of 
phytoplankton with mesoscale eddies remain poorly understood, even though there is a broad consensus that different sets of mechanisms dominate in different regions and at different times, and that the different polarity of the mesoscale eddies tends to induce signals of opposite sign (Denman and Gargett, 1995; Lévy, 2008; McGillicuddy Jr., 2016).

Lateral advection arising from local stirring of eddies has been argued to be a major driver globally. The argument is based on the observed correlation of the magnitude of eddyassociated $\mathrm{Chl}$ anomalies $(\delta \mathrm{Chl})$ and the larger-scale $\mathrm{Chl}$ gradient ambient to eddies (Doney et al., 2003; Uz and Yoder, 2004; Chelton et al., 2011a; O'Brien et al., 2013). Further, it has been suggested that advection of Chl by eddies via trapping, i.e., the enclosing and dragging along of water masses, causes $\delta \mathrm{Chl}$ (Gaube et al., 2014), particularly in boundary current regions characterized by steep zonal Chl gradients. Numerous other potential mechanisms through which eddies affect phytoplankton have been identified (e.g., Bracco et al., 2000; McGillicuddy Jr. et al., 2007; D'Ovidio et al., 2010; Gruber et al., 2011; Siegel et al., 2011; Gaube et al., 2013, 2014; Dufois et al., 2016), including vertical and lateral advection of nutrients, restratification and vertical mixing, and providing spatial niches through isolation of water parcels. These mechanisms modulate the phytoplankton's light exposure, their nutrient availability or their grazing pressure, i.e., they affect their net balance between growth and decay. Thus, in contrast to the physical mechanisms of stirring and trapping where phytoplankton is merely passively being advected, these mechanisms create eddy-associated phytoplankton biomass anomalies by altering their biogeochemical rates.

In the Southern Ocean, an area of light and iron limitation of phytoplankton (Boyd, 2002; Venables and Meredith, 2009), with distinct Chl heterogeneity (Comiso et al., 1993), and abundant with mesoscale eddies (e.g., Frenger et al., 2015), individual eddies haven been found to modulate $\mathrm{Chl}$ through many of the processes described above (e.g., Strass et al., 2002; Kahru et al., 2007; Ansorge et al., 2010; Lehahn et al., 2011). Here, we aim (i) to provide a reference estimate of the average seasonal $\mathrm{Chl}$ anomalies associated with mesoscale eddies in the different regions of the Southern Ocean, distinguishing anticyclones and cyclones, and (ii) to discuss the mechanisms likely causing the observed average imprint. Previous studies have used eddy kinetic energy as a proxy for eddy activity rather than sea level anomalies (SLA), which does not allow a distinction by polarity of eddies (Comiso et al., 1993; Doney et al., 2003), did not focus on the Southern Ocean (Chelton et al., 2011a; Gaube et al., 2014), or lacked a discussion of the seasonality of the relationship. In this study we show that the imprint of cyclones and anticyclones on Chl is mostly of opposite sign, largely zonal, and features a substantial seasonality along the ACC. Our results indicate that most of this mesoscale imprint can be explained by advection of Chl by mesoscale eddies.
Our approach is to identify individual eddies based on satellite estimates of SLA and combine those with satellite estimates of Chl (Chelton et al., 2011a; Gaube et al., 2014). We discuss possible mechanisms playing a role based on large-scale Chl gradients (Doney et al., 2003; Chelton et al., 2011a; Gaube et al., 2014) and the local shape of the average imprint of eddies on Chl (Chelton et al., 2011a; Siegel et al., 2011; Gaube et al., 2014).

\section{Methods and data}

We first introduce our analysis framework before describing the methods and data sources. This allows us to explain the approaches we use to assess the potential mechanisms explaining the $\delta \mathrm{Chl}$ associated with Southern Ocean mesoscale eddies.

\subsection{Analysis framework}

Fundamentally, mesoscale eddies can lead to local phytoplankton biomass anomalies through either advective processes, i.e., the spatial reshaping of existing gradients, or through biogeochemical fluxes and transformations that lead to anomalous growth or losses of biomass. In the following, we present these potential mechanisms in more detail, and how we estimate their importance.

\subsubsection{Causes of $\delta \mathrm{Chl}$ by advective processes}

Mesoscale eddies may cause $\delta \mathrm{Chl}$ as they laterally move waters (i.e., horizontally advect waters) including their $\mathrm{Chl}$ characteristics. This mechanism may lead to $\delta \mathrm{Chl}$ if (i) a lateral Chl gradient is present that is sufficiently steep at the spatial scale of the eddy-induced advection (Gaube et al., 2014), and (ii) the time scale of advection matches the time scale of phytoplankton biomass changes (Abraham, 1998). The latter time scale is in the order of days to weeks, possibly months, with the lower boundary representing roughly the reactivity time scale of phytoplankton biomass governed largely by the growth rate of the phytoplankton, and the upper boundary the potential sustenance of phytoplankton biomass via recycling of nutrients within the mixed layer. In regard to the spatial scale of advection by eddies, we distinguish two effects, that we have labeled stirring and trapping.

Stirring (Siegel et al., 2008; Chelton et al., 2011a; Gaube et al., 2014; McGillicuddy Jr., 2016) refers to the local distortion of a large-scale $\mathrm{Chl}$ gradient due to the rotation of an eddy, as illustrated in Fig. 1a, left column. The turnover time scale associated with the rotation of eddies is in the order of days to a few weeks, matching the time scales of phytoplankton reactivity. The spatial scale of stirring is given by the spatial extent of an eddy and is somewhat larger than the eddy core, as defined based on the Okubo-Weiss parameter (Frenger et al., 2015), that is several tens to several hundreds of kilometers. 
Next to stirring, eddies advect material properties due to their intrinsic lateral propagation (Fig. 1a, right column). We refer to the ability of eddies to transport fluid along their propagation pathway in their core as trapping (e.g., Flierl, 1981; Gaube et al., 2014; McGillicuddy Jr., 2016). The upper time scale of trapping is given by the typical lifespan of Southern Ocean mesoscale eddies, which is weeks to months (Frenger et al., 2015), it may thus match the longer time scale of phytoplankton biomass changes. Propagation speeds are low (an order of magnitude smaller than rotational speeds), which implies that the majority of eddies tends to die before they can propagate far. Thus, the fraction of very long-lived eddies that propagate over distances exceeding a few hundred kilometers is small (Frenger et al., 2015).

A necessary condition for trapping to happen is that the eddies' swirl velocity is larger than their propagation speed (Flierl, 1981), a condition generally met for mid- to highlatitude eddies (Chelton et al., 2011b). Indeed, observations of eddies carrying the signature of their origin in their cores support the trapping effect (Bernard et al., 2007; Ansorge et al., 2010; Lehahn et al., 2011), as does the modeling study by Early et al. (2011). Even though the trapping is never perfect (Beron-Vera et al., 2013; Haller, 2015), we expect eddies to be able to drag along some entrained waters for some time, hence displacing these waters for some distance as they propagate. This may be sufficient to displace waters from e.g., the south to the north of an ACC front along an intense Chl gradient, leading to $\delta \mathrm{Chl}$ through (permeable) trapping.

\subsubsection{Causes of $\delta \mathrm{Chl}$ by local biogeochemical processes}

Mesoscale eddies affect the biogeochemical and physical properties that control the local rates of growth and loss of phytoplankton (biogeochemical rates) in their interior through many mechanisms. These include the stimulation of phytoplankton growth through enhanced nutrient concentrations or increased average light levels, or the modification of predator-prey encounter rates, affecting the mortality of phytoplankton (Fig. 1b). Even though these effects have been analyzed and discussed for decades (see review by McGillicuddy Jr., 2016), their overall impact on productivity continues to be an issue of debate. The canonical lifelong vertical pumping of nutrients by thermocline lifted cyclones (Falkowski et al., 1991, indicated as black circle in Fig. 1b) has been challenged (e.g., Oschlies, 2002; Gaube et al., 2014), and multiple other mechanisms have been proposed on how eddies may affect phytoplankton biogeochemical rates. These include a modification of vertical mixing through changes in stratification (wiggly lines in Fig. 1b) and eddy current-wind interactions causing thermocline displacements (eddy swirl currents and winds are indicated as black and thick white arrows in Fig. 1b), resulting in modifications of nutrient supply and light availability to phytoplankton (e.g., Llido, 2005; McGillicuddy Jr. et al., 2007; Mahadevan et al., 2008; Lehahn et al., 2011; Siegel et al.,
2011; Xiu et al., 2011; Boyd et al., 2012; Mahadevan et al., 2012; Dufois et al., 2016). The prevailing lack of temporally sufficiently highly resolved subsurface observations hampers a systematic large-scale observationally based assessment of the role of effects of mesoscale eddies on the local biogeochemical processes.

\subsubsection{Assessing mechanisms causing $\delta \mathrm{Chl}$}

We employ two sets of approaches to assess the mechanisms causing $\delta \mathrm{Chl}$. In the first we diagnose whether the environmental conditions are supporting a major contribution of a particular set of mechanisms. Namely, we assess if lateral Chl gradients sufficiently support advective effects of eddies to explain $\delta \mathrm{Chl}$ (see Sect. 2.3 for technical detail).

In the second set we diagnose the shape of $\delta \mathrm{Chl}$ associated with eddies as this spatial signature tends to differ between the two major sets of processes, i.e., the advective process stirring and biogeochemical rates (Siegel et al., 2011). Eddies that stir are anticipated to have a dipole shaped $\delta \mathrm{Chl}$ (Fig. 1a, left column), as they distort the underlying gradient field, with the rotation of the eddy determining the orientation of the dipole. In contrast, most mechanisms associated with modifications of the biogeochemical rates cause a monopole shape, irrespective of polarity (Fig. 1b). This is a consequence of the mesoscale $\delta \mathrm{Chl}$ tending to be caused by anomalies in nutrient supply or light exposure, which are altered inside eddies in a radially symmetric manner. The advective trapping mechanism tends to also cause a monopole shape of $\delta \mathrm{Chl}$ (Fig. 1a, right column), but rate-based mechanisms can be distinguished from trapping for instance by their history (McGillicuddy Jr., 2016). Here we diagnose these as a residual: Rate-based mechanisms presumably play a role in regions and seasons where advective effects are insufficient to explain the observed eddy-induced $\delta \mathrm{Chl}$.

Some complexity is added to the interpretation of the spatial signature by the fact that the dipole shape arising from stirring tends to be asymmetric (Fig. 1a). Such an asymmetry was suggested by Chelton et al. (2011a) to arise from the westward propagation of eddies and the leading (mostly western) side of an eddy affecting upstream unperturbed waters, resulting in a larger anomaly at the leading compared to the trailing side of an eddy, with the latter stirring already perturbed waters. Also, the eddy may entrain some of the westward upstream waters into its core, labeled here lateral entrainment or permeable trapping (Hausmann and Czaja, 2012; Frenger et al., 2015). Indeed, averaged over an eddy's core, stirring will only cause a net anomaly if the dipole associated with stirring is asymmetric. It is not obvious how to quantify this effect. Independent of the dipole asymmetry, we will assess the potential maximum $\delta \mathrm{Chl}$ induced by stirring (see Sect. 2.4 for technical detail). We note that advection by an ambient larger-scale flow does not affect the stirring mechanism. For instance, the eastward Antarctic circumpolar flow in the Southern Ocean makes eddies propagate east- 
(a) Lateral Chl advection

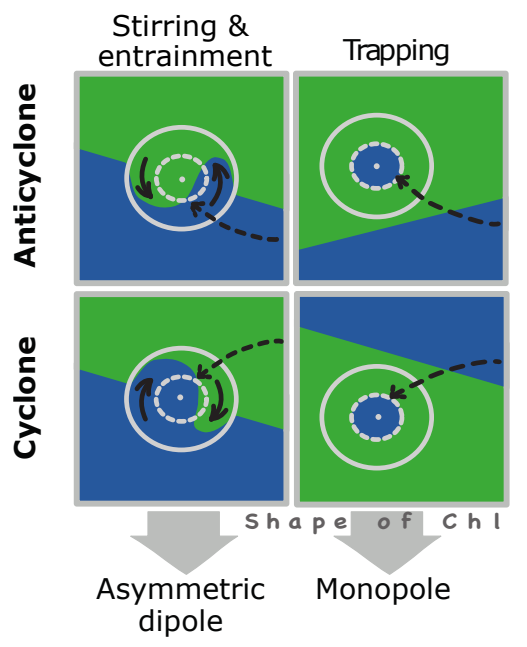

(b) Local Chl change

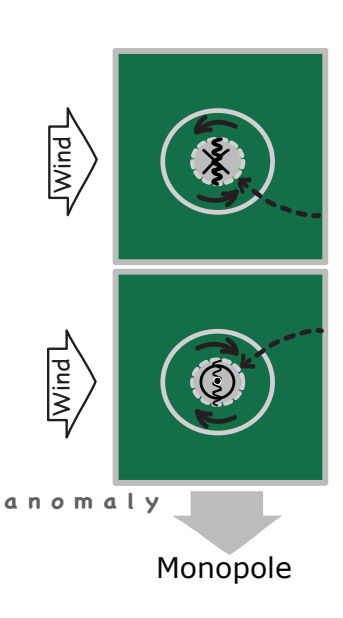

Chl intensity low

$\int \mathrm{Chl}$ intensity high

Chl intensity intermediate

Chl intensity modification of either sign

Eddy core

- Eddy edge

$\uparrow$ Eddy rotation

$\mathbf{k}^{-0}$ Eddy propagation

\{ Stronger or $\xi$ weaker vertical mixing

$X$ Deepened or $\odot$ lifted thermocline

Figure 1. Schematic illustrating the mechanisms of how eddies may impact chlorophyll (Chl), for anticyclones (top row) and cyclones (bottom row), for the southern hemisphere; (a) shows the effects of advection (lateral displacements) of Chl due to the eddies' rotational speed (stirring, left column) and lateral propagation (trapping, right column); trapping and stirring can cause $\delta$ Chl of either sign, depending on environmental Chl gradients; (b) shows multiple potential effects eddies may have on Chl by affecting biogeochemical processes. The local shape of $\delta \mathrm{Chl}$ is anticipated to look different depending on the mechanism active, i.e., a monopole $\delta \mathrm{Chl}$ is expected for all eddy-effects except for stirring where an asymmetric dipole is excepted (figure inspired by Siegel et al., 2011, Fig. 1).

ward in an Eulerian sense, while still propagating westward in a Lagrangian sense relative to the ACC and ambient Chl.

\subsection{Data}

To assess the relationship between ocean eddies and $\mathrm{Chl}$ anomalies, we use the data set of Southern Ocean eddies and their characteristics as derived and described in detail in Frenger et al. (2015). The data set contains more than 1000000 snapshots of mesoscale eddies identified in weekly maps of Aviso SLA (http://www.aviso.oceanobs.com/duacs/ Delayed-Time v3.0.0, reprocessed March 2010, last access: 2 August 2018) and defined based on the Okubo-Weiss parameter. Eddies with positive and negative SLA are defined as anticyclones and cyclones, respectively. We consider here only eddies tracked in the region 30 to $65^{\circ} \mathrm{S}$ over at least three weeks in the time period between 1997 and 2010, i.e., the operation time period of the SeaWIFS satellite-based sensor. The resolution capacity of Aviso SLA allows for the analysis of the larger mesoscale eddies with minimum diameters of about $50 \mathrm{~km}$ at $65^{\circ} \mathrm{S}$ and $100 \mathrm{~km}$ at $30^{\circ} \mathrm{S}$ (Chelton et al., 2011b; Frenger et al., 2015).

For Chl we use the ESA GlobColour Project product (http: //www.globcolour.info, version 2.0a1, last access: 2 August 2018, case-1 waters) which merges several sensors according to Maritorena and Siegel (2005), with a spatial and temporal resolution of $0.25^{\circ}$ and one day, respectively. We choose a merged product for $\mathrm{Chl}$ as the merging on average doubles the spatial coverage of the daily data in the Southern Ocean (Maritorena et al., 2010). Of the three available sensors, i.e., SeaWIFS (SeaStar), MODIS (Aqua) and MERIS (Envisat), SeaWIFS generally features the best spatio-temporal coverage, but its contribution drops below $40 \%$ in high latitudes and partly in the western ocean basins of the Southern Hemisphere. For these areas after 2002, SeaWIFS data were complemented with MODIS as well as MERIS data. We average the Chl data to weekly fields to match the temporal resolution of the eddy dataset. The combined eddy/Chl-dataset is publicly available at http://dx.doi. org/10.3929/ethz-b-000238826.

To examine the $\delta \mathrm{Chl}$ of eddies, we compare the $\mathrm{Chl}$ averaged over their core to background fields of Chl. For the latter, a monthly climatology of Chl proved not to be appropriate due to high spatio-temporal variability of Chl unrelated to eddies. Hence, we obtain the background fields the following way. We apply a moving spatio-temporal Gaussian filter (Weierstrass transform, spatial filter similar to Siegel et al. (2008), with $2 \sigma$ of 10 boxes $/ \sim 200 \mathrm{~km}$ at $45^{\circ} \mathrm{S}$, 8 boxes $/ \sim 200 \mathrm{~km}$ and 1 week in longitudinal, latitudinal and temporal dimensions, respectively) to each of the weekly Chl fields. We then subtract the result from the original fields to produce $\delta \mathrm{Chl}$ fields. The $\delta \mathrm{Chl}$ fields are not sensitive to the selected $\sigma$. The choice of a rather small spatio-temporal filter makes $\delta \mathrm{Chl}$ amplitudes smaller compared to the use of a larger filter, producing a conservative estimate of $\delta \mathrm{Chl}$. In order to generate spatial maps of $\delta \mathrm{Chl}$, we averaged all eddy associated anomalies of the respective eddy polarity into $5^{\circ} \times 3^{\circ}$ longitude/latitude boxes.

Prior to our analysis we log-transform Chl, due to $\mathrm{Chl}$ being lognormally distributed (Campbell, 1995). We frequently 
give $\delta \mathrm{Chl}$ in percentage difference relative to the background Chl as

$$
\begin{aligned}
\delta \mathrm{Chl}= & {\left[\exp \left(\log \left(\mathrm{Chl}_{\mathrm{e}}\right)-\log \left(\mathrm{Chl}_{\mathrm{bg}}\right)\right)-1\right] } \\
& \times 100=\left(\frac{\mathrm{Chl}_{\mathrm{e}}}{\mathrm{Chl}_{\mathrm{bg}}}-1\right) \times 100,
\end{aligned}
$$

with subscripts e and bg denoting eddy and background, respectively. Where we show absolute Chl on a logarithmic scale, we use the base 10 logarithm.

For the spatial analyses we use the positions of the main ACC fronts (Polar Front, PF, and Subantarctic Front, SAF) as determined by Sallée et al. (2008) and a climatology of sea surface height (SSH) contours (Maximenko et al., 2009), which are representative of the long-term geostrophic flow in the area. The mean positions of the PF and SAF align approximately with the mean SSH contours of -40 and $-80 \mathrm{~cm}$, respectively. We select the $-20 \mathrm{~cm} \mathrm{SSH}$ contour to separate waters of the southern subtropical gyres to the north of the ACC, referred to as subtropical waters from waters in the "ACC influence area", referred to as ACC waters. This choice is based on both, a tendency for net eastward propagation of eddies south of this contour (Frenger et al., 2015) indicating advection by the ACC mean flow, and a seasonal sign switch of $\delta \mathrm{Chl}$, which will be addressed later in the paper. Waters south of the $\mathrm{PF} /-80 \mathrm{~cm}$ SSH will be referred to as Antarctic waters. Finally, we use mixed layer depths derived from Argo floats, available at http://www.locean-ipsl.upmc.fr (last access: 2 August 2018) (Argo, 2000).

\subsection{Analysis of environmental Chl conditions}

Using the data presented in the previous section, we calculate a monthly Chl climatology. Based on this climatology, we derive the potential $\delta \mathrm{Chl}(\hat{\delta} \mathrm{Chl})$ eddies may induce due to lateral advection (Fig. 1a). In order to assess the $\hat{\delta} \mathrm{Chl}$ emerging from stirring in the Southern Ocean $\left(\hat{\delta} \mathrm{Chl}_{\text {stir }}\right)$, we compute the absolute climatological meridional $\mathrm{Chl}$ gradient at the spatial scale of individual eddies, here taken as two eddy radii. We then assign a sign to $\hat{\delta} \mathrm{Chl}_{\text {stir }}$ according to the sign of the meridional $\mathrm{Chl}$ gradient and the cyclonicity of the eddy, given the intrinsic westward propagation of eddies. That is, we anticipate that, e.g., a southern hemispheric counterclockwise-rotating, i.e., anticyclonic eddy under conditions of northward increasing $\mathrm{Chl}$ will be associated with positive $\delta \mathrm{Chl}$ in its core (Fig. 1a, left column). In contrast, under the same ambient $\mathrm{Chl}$ conditions we anticipate negative $\delta \mathrm{Chl}$ for cyclones.

To assess the $\hat{\delta} \mathrm{Chl}$ emerging from trapping (Fig. 1a, right column), we estimate the Chl variation along individual eddies' pathways by computing the difference of the climatological $\mathrm{Chl}$ at the origin of an eddy and at its present location $\left(\hat{\delta} \mathrm{Chl}_{\text {trap }}\right)$. We use for this difference the climatological Chl at the month of the present location of the eddy to consider the effects of the seasonal $\mathrm{Chl}$ variations, assuming that po- tentially trapped Chl would seasonally covary with the Chl at the place of the eddy's origin.

\subsection{Analysis of the local shape of $\delta \mathrm{Chl}$}

We compute the composite spatial pattern of $\mathrm{Chl}$ and $\delta \mathrm{Chl}$ associated with mesoscale eddies the same way as was done by Frenger et al. (2015) for sea surface temperatures. We extract a squared subregion for each individual eddy from the weekly maps of SLA and Chl, centered at the eddy's center. The side lengths of the subregion are 10 eddy radii each, implying an implicit scaling according to the eddy size. We rotate the $\mathrm{Chl}$ snapshots according to the ambient $\mathrm{Chl}$ gradient and average them over all eddies to produce the eddy composite. Note that the estimate of the magnitudes of the dipole and the average ambient $\mathrm{Chl}$ gradient (see below) tend to be slightly weaker without rotation. Nevertheless, as averages are taken over regimes of largely similar orientation of the ambient Chl gradient (see Discussion Sect. 4), our conclusions do not depend on whether we rotate the snapshots or not.

Further, we decompose the composite spatial pattern $\delta \mathrm{Chl}$ into a monopole (MP) and dipole (DP) component by first constructing the monopole by computing radial averages of $\delta \mathrm{Chl}$ around the eddy's center, i.e., $\delta \operatorname{Chl}(r)_{\mathrm{MP}}=\overline{\delta \operatorname{Chl}(r)}$, where $r$ is the distance from the eddy's center. In the second step, we calculate $\delta \mathrm{Chl}_{\mathrm{DP}}$ as a residual, i.e., by differencing the monopole pattern from the total signal. Even though this residual approach captures in the dipole structure any non-monopole pattern, experience has shown that the $\delta \mathrm{Chl}_{\mathrm{DP}}$ typically feature dipoles (Frenger et al., 2015). In the final step, we quantify the amplitudes of the monopoles and the dipoles, assess the contribution of the two components to the spatial variance of the total signal based on the sum of variances $($ var $)$, i.e., $\operatorname{var}(\delta \mathrm{Chl})=\operatorname{var}\left(\delta \mathrm{Chl}_{\mathrm{MP}}\right)+\operatorname{var}\left(\delta \mathrm{Chl} \mathrm{DP}_{\mathrm{DP}}\right)$, and compute the Chl gradient at the scale of two eddy radii, as an estimate of the potential maximum contribution of stirring to $\delta \mathrm{Chl}$.

\subsection{Handling of measurement error and data gaps}

An individual eddy $\delta \mathrm{Chl}$ signal may be undetectable even with in situ measurements (Siegel et al., 2011), and it may be smaller than the error of the satellite retrieved Chl. The significance of our results, which we test based on $t$ tests, arises from the very large number of analyzed eddies, which totals about 600000 eddy snapshots across the entire Southern Ocean. This is substantially smaller than our original data set, largely due to the missing $\mathrm{Chl}$ data arising from frequent cloud cover in the Southern Ocean. For $33 \%$ of the eddies identified by SLA, the corresponding Chl data was entirely missing, and for $75 \%$ of eddies at least part of the data was missing. The average missing data over eddies due to cloud cover only (leaving aside missing data due to the polar night) increase from $18 \%$ at $30^{\circ} \mathrm{S}$ to $63 \%$ at $65^{\circ} \mathrm{S}$. Anticy- 
clones exhibit a higher percentage of data gaps than cyclones ( $48 \%$ vs. $42 \%$ averaged over the Southern Ocean), which can be explained by the impact of their sea surface temperature anomalies on cloud cover (Park et al., 2006; Small et al., 2008; Frenger et al., 2013).

\section{Results}

\subsection{Imprint of mesoscale eddies on Chl}

\subsubsection{Mean imprint}

Averaged across the entire Southern Ocean and all seasons, we detect a significant, although small, mean imprint of mesoscale eddies on Chl (Fig. S1 in the Supplement) for both anticyclonic (warm-core, high SLA, and deepened thermocline) and cyclonic (cold-core, low SLA, and lifted thermocline) eddies. The overall mean $\delta \mathrm{Chl}$ associated with anticyclones is $-4 \%$, while that for cyclones is of even smaller magnitude, i.e., $+1 \%$. Though small, both anomalies are actually statistically significant $(p<0.05)$. However, the distributions around these means are very broad, with many anticyclones and cyclones having both positive or negative $\delta \mathrm{Chl}$, depending on the region and time of the year. The long tails of the distributions, corroborated by visual inspection of the individual $\delta \mathrm{Chl}$ of eddies, suggest anomalies that are substantially larger than the mean. Thus, it appears that by averaging the signals in time and space, a substantial amount of information is lost. As a consequence, it is more insightful to disentangle the signals and to examine the regional and seasonal variation of $\delta \mathrm{Chl}$.

\subsubsection{Spatial variability of imprint}

The maps of the annual mean imprint of cyclonic and anticyclonic eddies on Chl clearly support the hypothesis of a strong regional cancellation effect (Fig. 2). First, the regional mean signal associated with eddies is indeed much larger than suggested by the mean $\delta \mathrm{Chl}$ across the entire Southern Ocean. In fact, around a quarter of the analyzed grid cells have absolute $\delta \mathrm{Chl}$ larger than $10 \%$, with the mean absolute $\delta \mathrm{Chl}$ exceeding several tens of percent in a substantial number of grid cells (Fig. 2b, c). Second, the signals associated with mesoscale eddies of either polarity vary in sign across the different regions with regions of strong enhancements bordering regions with strong reductions (see also Fig. 1 in Gaube et al., 2014). In the broadest sense, the pattern is zonal in nature, reflecting the zonal nature of the climatological $\mathrm{Chl}$ distribution (Fig. 2a).

For anticyclones, $\delta \mathrm{Chl}$ is clearly negative in subtropical waters, i.e., the waters north of the $\mathrm{SSH}=-20 \mathrm{~cm}$, and in the regions around the western boundary currents (Fig. 2b). These prevailing negative $\delta \mathrm{Chl}$ are contrasted by mostly positive $\delta \mathrm{Chl}$ along the ACC. Cyclones have a largely similar spatial pattern, but of opposite sign (Fig. 2c). That is, pre- vailing positive $\delta \mathrm{Chl}$ in subtropical waters are mirrored by a band of negative, yet weaker anomalies along the ACC. South of the ACC, in Antarctic waters, the pattern of $\delta \mathrm{Chl}$ is spotty for anticyclones as well as cyclones, with anticyclones and cyclones featuring average positive and negative $\delta \mathrm{Chl}$, respectively. In summary, SLA and $\delta \mathrm{Chl}$ are largely negatively correlated in subtropical waters north of the ACC, and positively correlated along the ACC.

A few exceptions break the mostly zonal pattern for Chl (Ardyna et al., 2017), and also for $\delta \mathrm{Chl}$. An exceptional area of negative $\delta \mathrm{Chl}$ for cyclones in the subtropical waters of the eastern Indian Ocean disrupts the zonal band of largely positive anomalies. Also, $\delta \mathrm{Chl}$ in shelf areas often are distinct from open-ocean $\delta \mathrm{Chl}$. A clear signal emerges south of the Australian and west of the South American coasts, west of New Zealand, and more subtly, east of the Kerguelen Islands and the Drake Passage (see also Sokolov and Rintoul, 2007; d'Ovidio et al., 2015), where $\delta \mathrm{Chl}$ tends to be positive for both anticyclones and cyclones.

\subsubsection{Seasonality of imprint}

The pronounced zonal bands of $\delta \mathrm{Chl}$ for mesoscale anticyclones and cyclones persist over the year, but tend to migrate meridionally (Fig. 3a-d, middle and right columns), thereby following the pronounced seasonality of $\mathrm{Chl}$ (Fig. 3a-d, left column; Thomalla et al., 2011; Sallée et al., 2015; Ardyna et al., 2017). The seasonality of $\delta \mathrm{Chl}$ is larger along the $\mathrm{ACC}$ and in Antarctic waters compared to subtropical waters. In the subtropical gyres, $\delta \mathrm{Chl}$ of anticyclones and cyclones are negative and positive, respectively, i.e., SLA and $\delta \mathrm{Chl}$ are negatively correlated all year round. Here, $\delta \mathrm{Chl}$ shows a weak peak in austral summer when climatological $\mathrm{Chl}$ is lowest (Fig. 3c). In the ACC regions and in Antarctic waters, a striking feature is the seasonal change in the sign of $\delta \mathrm{Chl}$ for both cyclones and anticyclones (Fig. 3b-d).

This becomes even more evident when inspecting the zonally averaged $\mathrm{Chl}$ and $\delta \mathrm{Chl}$ as a function of season and $\mathrm{SSH}$, i.e., plotted in the form of a Hovmoeller diagram (Fig. 4). Along the ACC, anticyclones exhibit negative $\delta \mathrm{Chl}$ in winter to spring concurrent with deep mixed layers, followed by positive $\delta \mathrm{Chl}$ from summer to autumn (Fig. 4b). Cyclonic $\delta \mathrm{Chl}$ shows an opposite pattern, featuring negative $\delta \mathrm{Chl}$ from summer to autumn, with near to zero to positive $\delta \mathrm{Chl}$ in winter to spring (Fig. $4 \mathrm{c}$ ). This implies that SLA and $\delta \mathrm{Chl}$ are positively correlated summer to autumn, followed by a negative correlation in winter to spring. The sign switch of the correlations shows a seasonal lag towards Antarctic waters, with positive correlations prevailing from autumn to winter, and negative correlations prevailing from spring to summer, resulting in the aforementioned apparent southward migration of the sign switch of the $\delta \mathrm{Chl}$ over the course of the year. 
(a) $\log (\mathrm{Chl})$ background
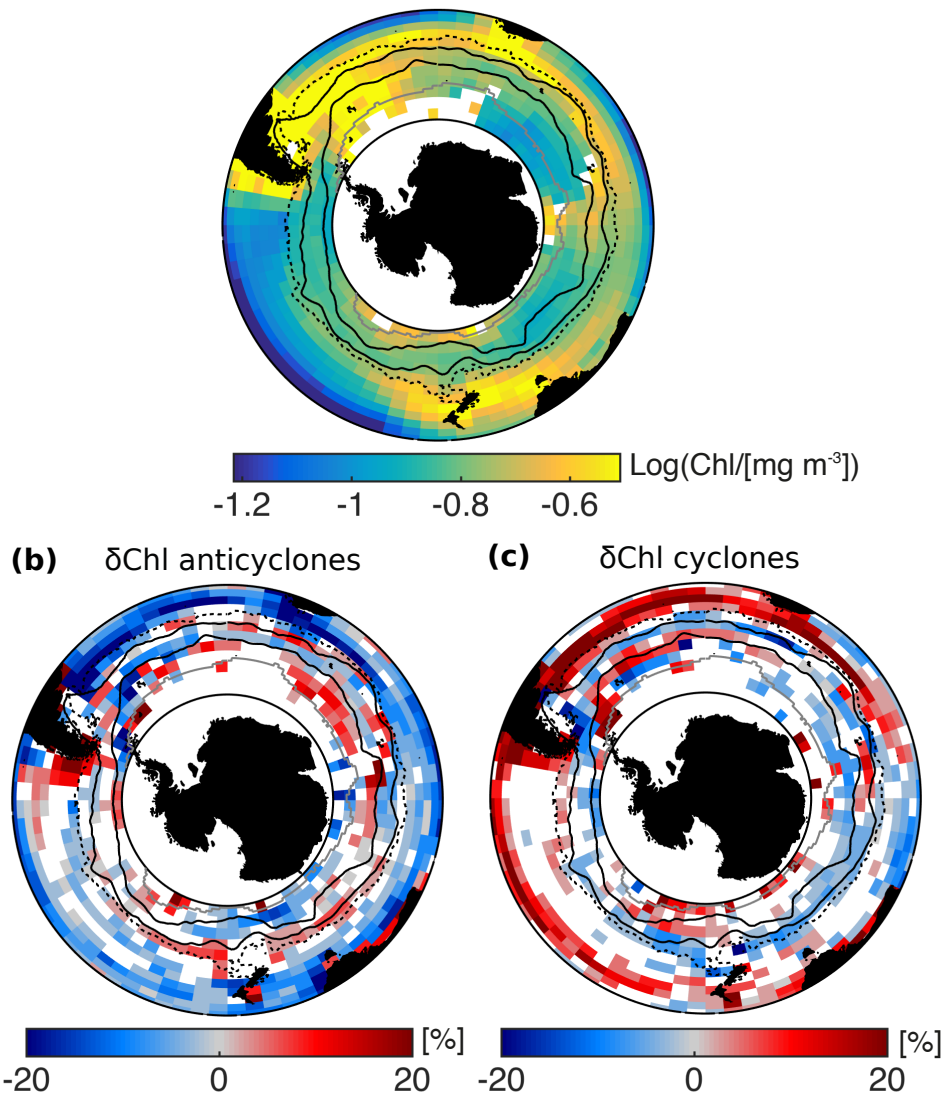

Figure 2. Spatial distribution of chlorophyll anomalies $(\delta \mathrm{Chl})$ associated with eddies; (a) logarithm (base 10) of annual climatological Chl for reference, and mean $\delta \mathrm{Chl}$ of (b) anticyclones and (c) cyclones; $\delta \mathrm{Chl}$ is the average of anomalies of eddies lasting at least 3 weeks in $5^{\circ} \times 3^{\circ}$ longitude-latitude grid boxes; white boxes indicate insufficient data (less than three data points) or anomalies insignificantly different from zero ( $t$ test, $p=0.05$ ); solid black lines mark the main branches of the ACC (the Subantarctic Front and Polar Front); the dashed black line denotes the $-20 \mathrm{~cm} \mathrm{SSH}$ contour and the solid gray line the northernmost extension of sea-ice cover.

\subsection{Causes for the imprint}

\subsubsection{Advection}

To assess the contribution of advective mechanisms to the observed $\delta \mathrm{Chl}$, we contrast it with the potential of eddies to cause $\delta \mathrm{Chl}$ through $\mathrm{Chl}$ advection, that is with the potentials $\hat{\delta} \mathrm{Ch}_{\text {stir }}$ associated with stirring and $\hat{\delta} \mathrm{Chl}_{\text {trap }}$, associated with trapping (Fig. 4d-g, Method Sect. 2.3). The closer the observed $\delta \mathrm{Chl}$ is to these parameters, the more important the respective processes would be in causing this signal.

In the northern domain, i.e., in subtropical waters, the sign of $\hat{\delta} \mathrm{Chl}_{\text {stir }}$ tends to agree with $\delta \mathrm{Chl}$ throughout the year for both anticyclones and cyclones (Fig. 4b-e). So does the seasonal variation of the magnitude of $\hat{\delta} \mathrm{Chl}_{\text {stir }}$, with the largest magnitudes found from summer to autumn. Also the regional variations match, such as a weaker $\hat{\delta} \mathrm{Chl}_{\text {stir }}$ and $\delta \mathrm{Chl}$ in the Pacific sector compared to the Atlantic and Indian Ocean sectors (Fig. 3, middle and right columns and Supplement Fig. S2, left column).

Furthermore, along the ACC and its northern flank, $\hat{\delta} \mathrm{Chl}_{\text {stir }}$ and $\delta \mathrm{Chl}$ agree in sign, and are of the same order of magnitude from summer to autumn. Finally, along the southern ACC and in Antarctic waters, $\hat{\delta} \mathrm{Ch}_{\text {stir }}$ mirrors the seasonal sign switch of $\delta \mathrm{Chl}$, and the apparent seasonal southward migration of the zonal bands of $\delta \mathrm{Chl}$ (Figs. 3 and $4 \mathrm{~b}-\mathrm{e}$ ). Thus, it appears that stirring can already explain a good fraction of the observed $\delta \mathrm{Chl}$ (i) in subtropical waters outside of those characterized by winter deep mixed layers, (ii) along the ACC and its northern flank from summer to autumn, and (iii) south of the ACC.

The reason underlying the strong potential of stirring is the presence of strong lateral gradients of Chl. For instance, averaged over mesoscale eddies in northern subtropical waters from winter to spring (Method Sect. 2.4), the absolute ambient gradient of $\mathrm{Chl}$ at scales of two eddy radii is $7 \%$ for both anticyclones and cyclones, compared to the absolute maxi- 

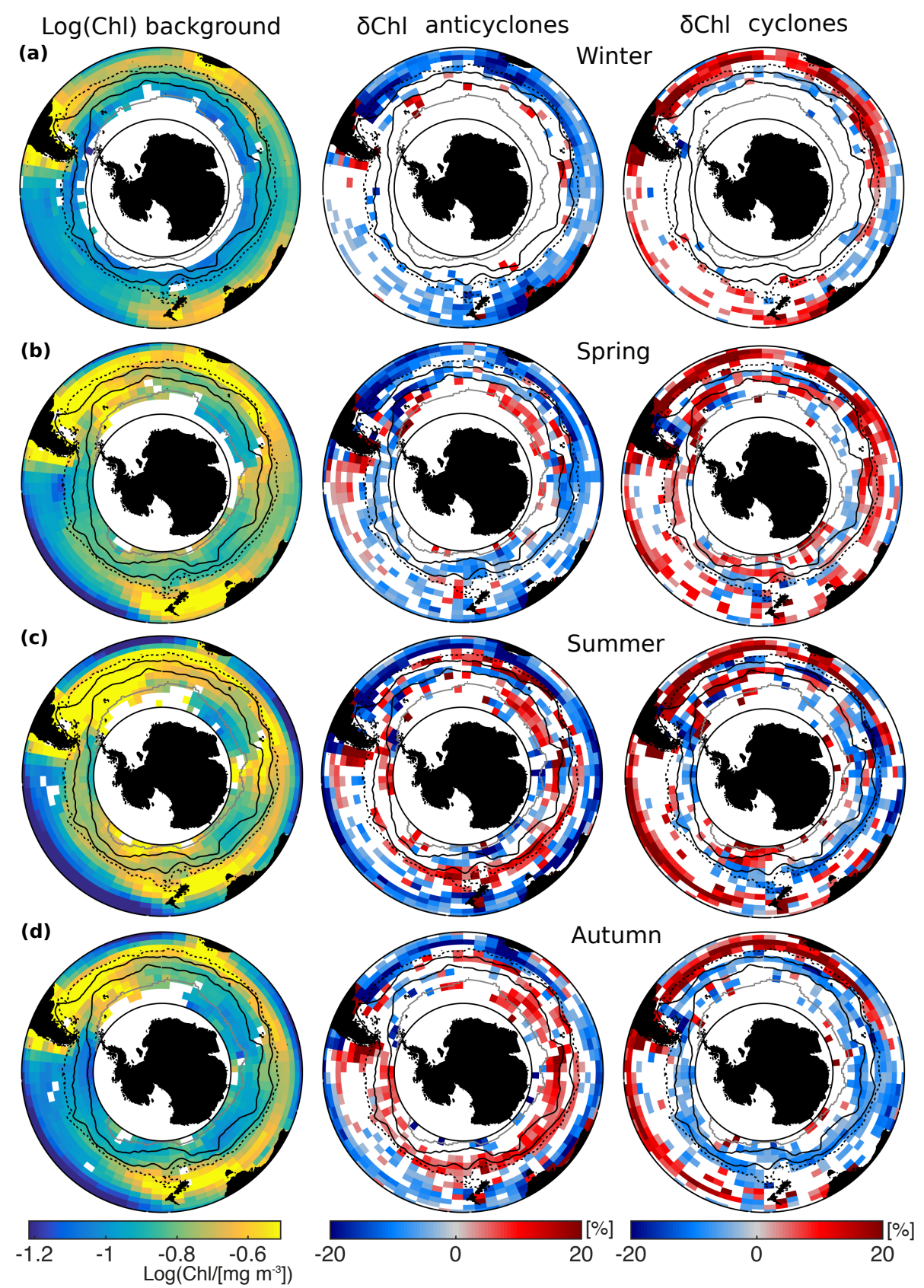

Figure 3. Seasonality of chlorophyll anomalies ( $\delta \mathrm{Chl})$ associated with eddies; austral (a) winter (JJA), (b) spring (SON), (c) summer (DJF), and (d) autumn (MAM) for anticyclones (middle) and cyclones (right); The logarithm (base 10) of seasonal climatological Chl is shown for reference (left). Otherwise the same as Fig. 2.

mum $\delta \mathrm{Chl}$ of $10 \%$ and $9 \%$, respectively (Fig. 5a, see numbers at the bottoms of left two panels). A similar correspondence is found along the ACC and its northern flank from summer to autumn (Fig. 6a), and in Antarctic waters during spring (Fig. 5b), supporting that stirring alone may largely explain the observed $\delta \mathrm{Chl}$ (Fig. 6a; anticyclones: gradient of $9 \%$ and maximum $\delta \mathrm{Chl}$ of $5 \%$; cyclones: gradient of $9 \%$ and maximum $\delta \mathrm{Chl}$ of $11 \%$; and Fig. 5 b; anticyclones: gra- dient of $5 \%$ and maximum $\delta \mathrm{Chl}$ of $6 \%$; cyclones: gradient of $5 \%$ and maximum $\delta \mathrm{Chl}$ of $5 \%$ ).

The advective potential for the other lateral advective mechanism, i.e., trapping, $\hat{\delta} \mathrm{Chl}_{\text {trap }}$, partly counteracts and partly enhances $\hat{\delta} \mathrm{Ch}_{\text {stir }}$ (Fig. $4 \mathrm{~d}-\mathrm{g}$ ). For instance, for cyclones along the ACC from summer to autumn, trapping possibly contributes to a $\delta \mathrm{Chl}$ signal (11\%) that is slightly larger than the $\mathrm{Chl}$ gradient at two eddy radii (9\%), and the con- 

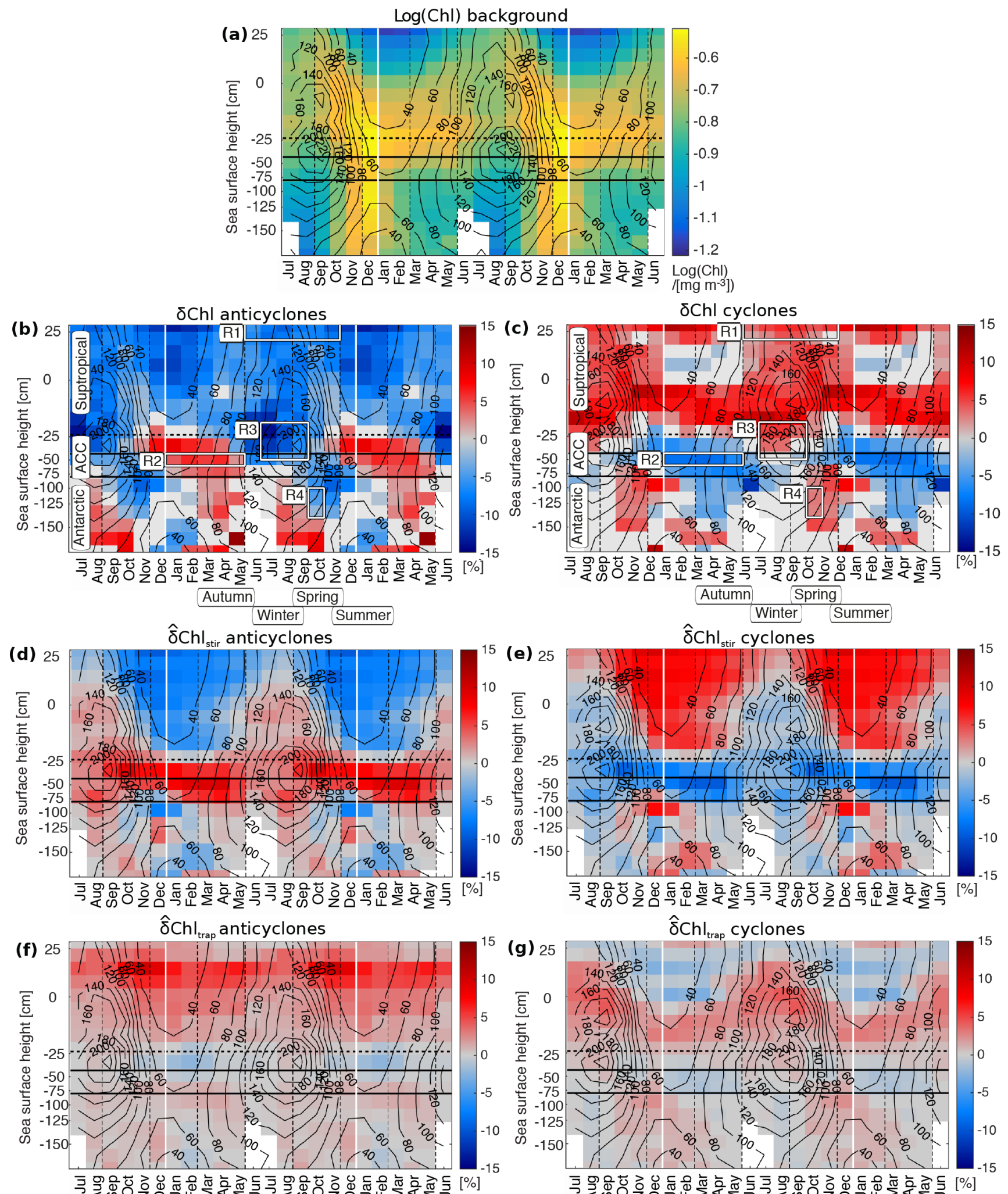

Figure 4. Seasonality of chlorophyll anomalies $(\delta \mathrm{Chl})$ associated with eddies, and potential of eddies to cause $\delta \mathrm{Chl}$ through lateral advection, i.e., $\hat{\delta} \mathrm{Chl}$ stir for stirring and $\hat{\delta} \mathrm{Ch} l_{\text {trap }}$ for trapping. (a) Base 10 logarithm of monthly climatological $\mathrm{Chl}$ for reference; (b, c) $\delta \mathrm{Chl}$ related to anticyclones and cyclones, respectively; (d, e) advective potential (Sect. 2.3 ) due to stirring by anticyclones and cyclones, respectively; (f, g), advective potentials due to trapping by anticyclones and cyclones, respectively. In panels (a)-(c), Chl and $\delta$ Chl are the mean of all eddies lasting at least 3 weeks binned in monthly sea surface height (SSH) bins so that boxes roughly cover equal areas; in panels (b, c) white boxes indicate regions R1 to R4 used for composite Figs. 5 and 6. In all subpanels, values that are not significant ( $t$ test, $p>0.05$ ) are colored in light gray, insufficient data (less than three data points) in white; solid black lines mark the ACC (approximate positions of the Subantarctic Front and Polar Front); the horizontal dashed black line denotes the -20 cm SSH contour, the vertical dashed lines seasons; solid black contours show averaged mixed layer depths in meters; note that the seasonal cycle is shown repeatedly to highlight cyclic patterns. 

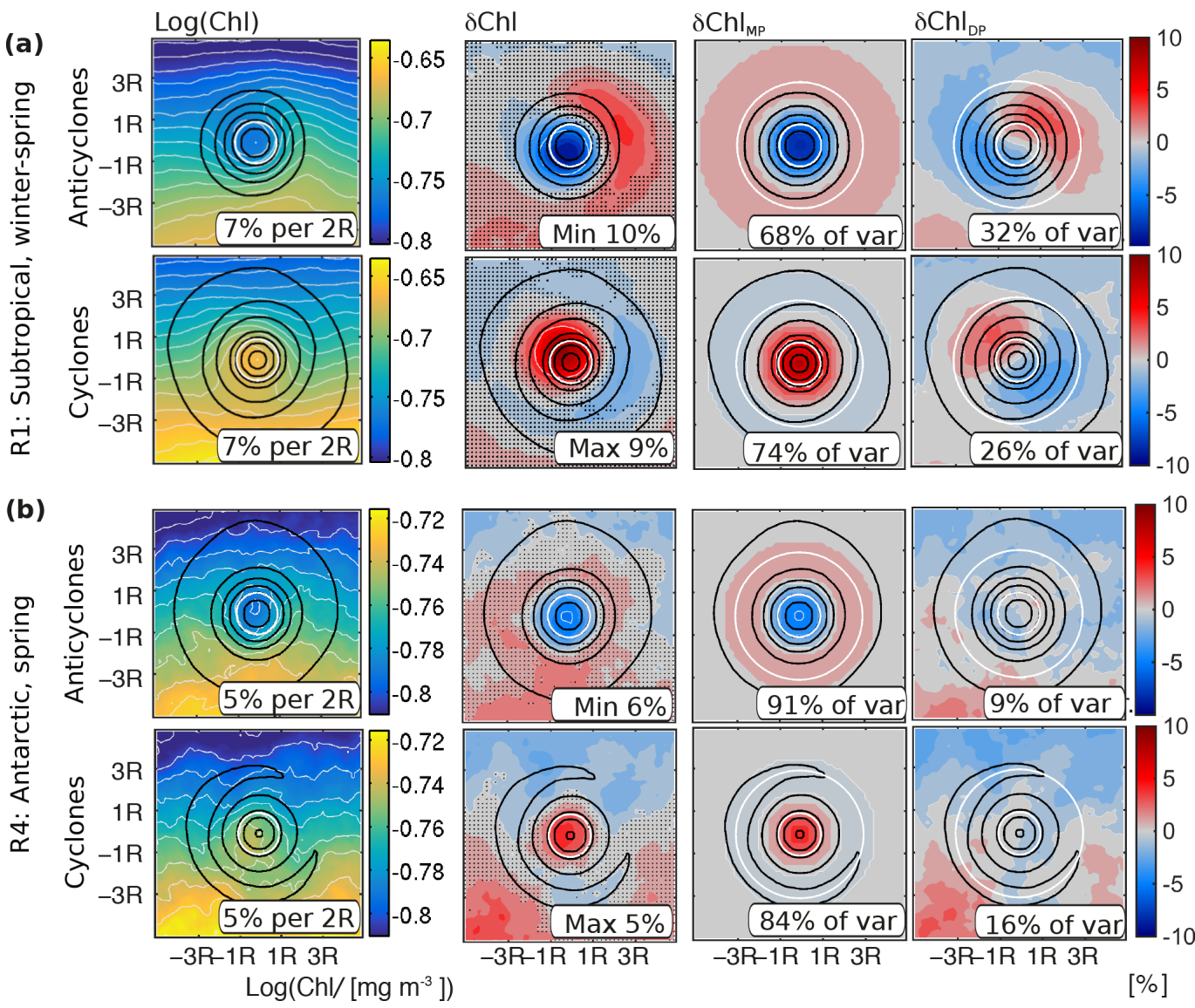

Figure 5. Attribution of stirring/trapping components of mesoscale eddy associated Chl; (a) average instantaneous Chl and $\delta \mathrm{Chl}$ (see Method Sect. 2.4) in region R1 (SSH larger $10 \mathrm{~cm}$, June to November) and (b) in region R4 (SSH -140 to $-100 \mathrm{~cm}$, October), indicated as white boxes in Figs. 4b, c and 7. Within each subpanel, the top rows show the results for the anticyclones, and the bottom rows for the cyclones. The left column shows the logarithm (base 10) of Chl, the middle left the $\delta \mathrm{Chl}$ (stippling marks insignificant anomalies), the middle right one the monopole component, MP, and the right one the residual component (approximately a dipole component, DP; see text for details and cartoon in Fig. 1). The sea level anomaly contours are shown in black (normalized before averaging); the inner and outer white circles indicate the eddy core and area used for the computation of the contribution to the variance of $\delta \mathrm{Chl}$ of the monopole and the dipole, respectively; text in panels denotes (left) the meridional Chl gradient at two eddy radii, (second left) the maximum or minimum of the anomaly, (second right and right) the contribution to the variance of the anomaly pattern of the monopole and dipole, respectively; before averaging, the individual eddy snapshots are rotated according to the ambient instantaneous $\mathrm{Chl}$ gradient.

tribution of the variance of the monopole is increased compared to anticyclones (Fig. 6a, $96 \%$ versus $87 \%$ ). Yet, overall the trapping potential $\hat{\delta} \mathrm{Chl}_{\text {trap }}$ is weak compared to $\delta \mathrm{Chl}$ (Fig. 4b, c, f, g), and outweighed by $\hat{\delta} \mathrm{Chl}_{\text {stir }}$.

\subsubsection{Local biogeochemical rates}

Even though advective processes, and particularly stirring, appear to be the dominant driver for the mesoscale eddyassociated $\mathrm{Chl}$ anomalies, there are nevertheless a few places where the magnitudes of the potentials for advective effects are too weak compared to the observed $\delta \mathrm{Chl}$ or of opposite sign. These are the places where variations in the local growth and loss processes, i.e., variations in the local biogeochemical rates, may be the dominant driver.
The most prominent instance is found along the northern ACC, a region associated with the seasonal sign switch of $\delta$ Chl (Fig. 4b-g, blue boxes in Fig. 7a). Here, anticyclones switch to negative $\delta \mathrm{Chl}$ in the presence of deep mixed layers, whereas both $\hat{\delta} \mathrm{Chl}_{\text {stir }}$ and $\hat{\delta} \mathrm{Ch} l_{\text {trap }}$ suggest positive $\delta \mathrm{Chl}$. The shape of the local imprint of anticyclones in the respective region and season (Fig. 6b) indicates that the lateral Chl gradient at the scale of eddies (5\%) is small compared to the maximum absolute amplitude of $\delta \mathrm{Chl}(17 \%)$. Further, the decomposition of the local shape of $\delta \mathrm{Chl}$ into a monopole and a dipole suggests that stirring (dipole) supports an anomaly of the opposite sign compared to the observed $\delta \mathrm{Chl}$, consistent with $\hat{\delta} \mathrm{Chl}_{\text {stir }}$ (Fig. 4d). Given that trapping would also cause a weak anomaly of the opposite sign (Fig. 4f), we hypothesize that eddy-induced changes in the biogeochemical rates 

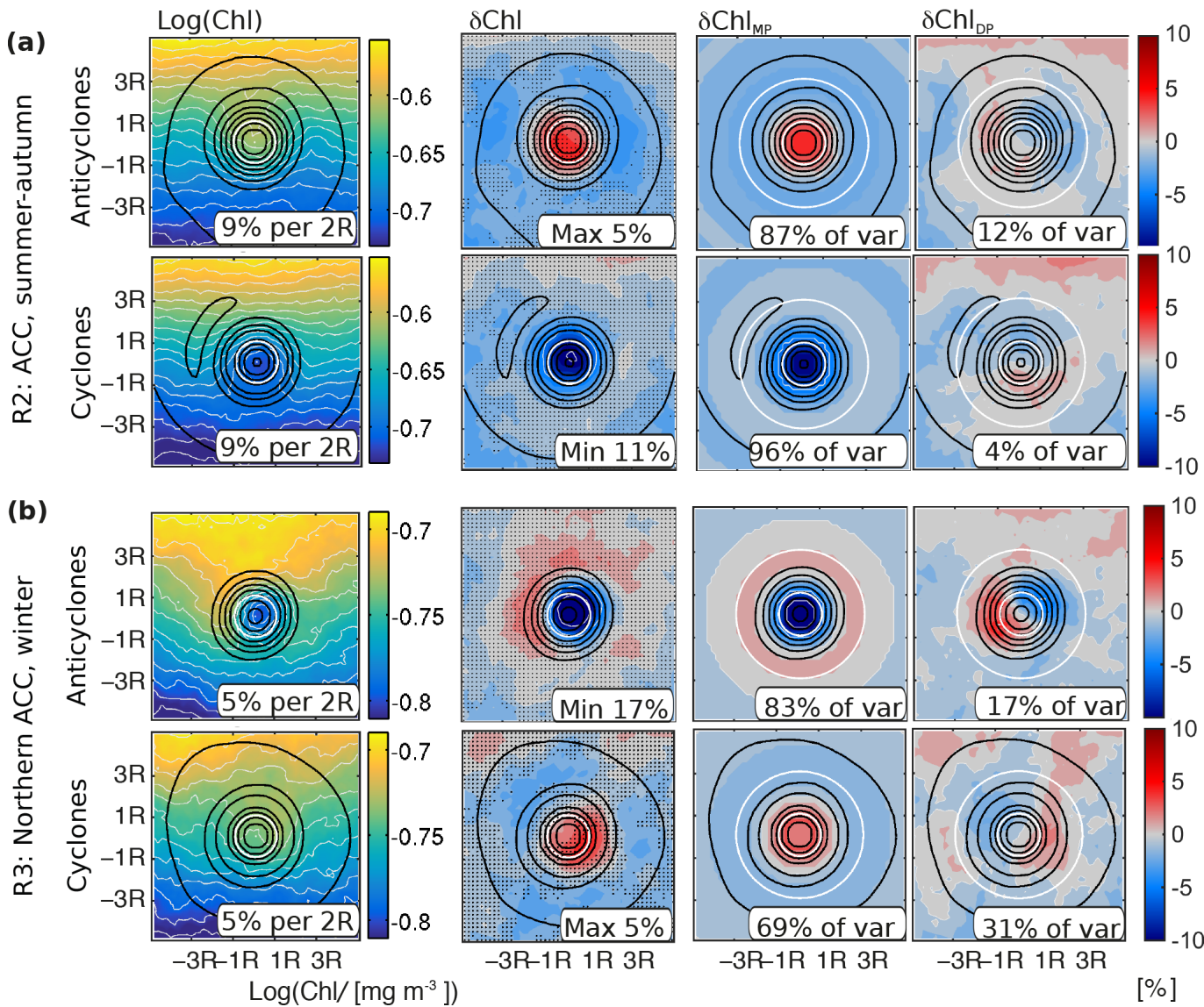

Figure 6. Attribution of stirring/trapping components; same as Fig. 5 but for (a) the region R2 (SSH -60 to $-40 \mathrm{~cm}$, January to May) and (b) for region $\mathrm{R} 3$ (SSH -50 to $-15 \mathrm{~cm}$, July to September). The regions are indicated with white boxes in Figs. $4 \mathrm{~b}$, c and 7.

are responsible for the negative $\delta \mathrm{Chl}$ in winter and spring in the northern ACC.

Similarly, the sign switch of $\delta \mathrm{Chl}$ of cyclones in the same region cannot be explained based on $\hat{\delta} \mathrm{Chl}_{\text {stir }}$ (Fig. 4e). The local shape of $\mathrm{Chl}$ corroborates that for cyclones stirring of the average ambient $\mathrm{Chl}$ gradient also induces an anomaly of the opposite sign (Fig. $6 \mathrm{~b}$ ). In contrast to $\hat{\delta} \mathrm{Ch} 1_{\text {stir }}, \hat{\delta} \mathrm{Ch} 1_{\text {trap }}$ for cyclones is of the same sign as $\delta \mathrm{Chl}$ (Fig. $4 \mathrm{~g}$ ), indicating a potential contribution of trapping to positive $\delta \mathrm{Chl}$ under deep mixed layers. Yet, as noted in the previous paragraph, the magnitude of $\hat{\delta} \mathrm{Chl}_{\text {trap }}$ is small, hence the contribution by trapping is limited. Further, trapping is not of the same sign as $\delta \mathrm{Chl}$ for cyclones everywhere in the region either (see blue boxes Fig. 8a,b, right column). Hence, the likely explanation for the $\delta \mathrm{Chl}$ in cyclones in regions with deep winter mixed layers is that eddies also modify the local biogeochemical rates.

Effects of eddies on biogeochemical rates also may play a role in other regions or seasons. For instance, the magnitudes of $\hat{\delta} \mathrm{Chl}_{\text {stir }}$ and $\hat{\delta} \mathrm{Chl}$ trap appear too weak to explain $\delta \mathrm{Chl}$ in subtropical waters in winter and spring (Figs. $4 \mathrm{~d}-\mathrm{g}$ and $5 \mathrm{a}$ ). Further, closed Chl contours are associated with the eddy cores that cannot originate from local lateral entrainment associated with stirring (Figs. 5 and 6, left columns). Also the generally weak potential $\hat{\delta} \mathrm{Ch}_{\text {trap }}$ fails to explain the closed $\mathrm{Chl}$ contours and the associated strong monopole component of $\delta \mathrm{Chl}$ that contributes about $70 \%$ to $100 \%$ to the variability of the $\delta \mathrm{Chl}$ shape (Figs. 4f, g, 5 and 6). These points both indicate that effects on biogeochemical rates enhance the $\delta \mathrm{Chl}$ monopole.

\section{Discussion and synthesis}

The zonal pattern of the $\delta \mathrm{Chl}$ identified here for the Southern Ocean is similar to that described by Gaube et al. (2014) across the world's oceans. Analogous to the results of our analyses, they also found spatial variations in the sign of $\delta \mathrm{Chl}$ associated with either cyclonic and anticyclonic eddies. Yet, there are also substantial differences, especially along the ACC, where, e.g., the $\delta \mathrm{Chl}$ is more widespread and more intense than previously acknowledged. Further, the seasonal variations in the Southern Ocean appear to be stronger than elsewhere (Gaube et al., 2014), except, perhaps, for the eastern Indian Ocean and the South China Sea (Gaube et al., 


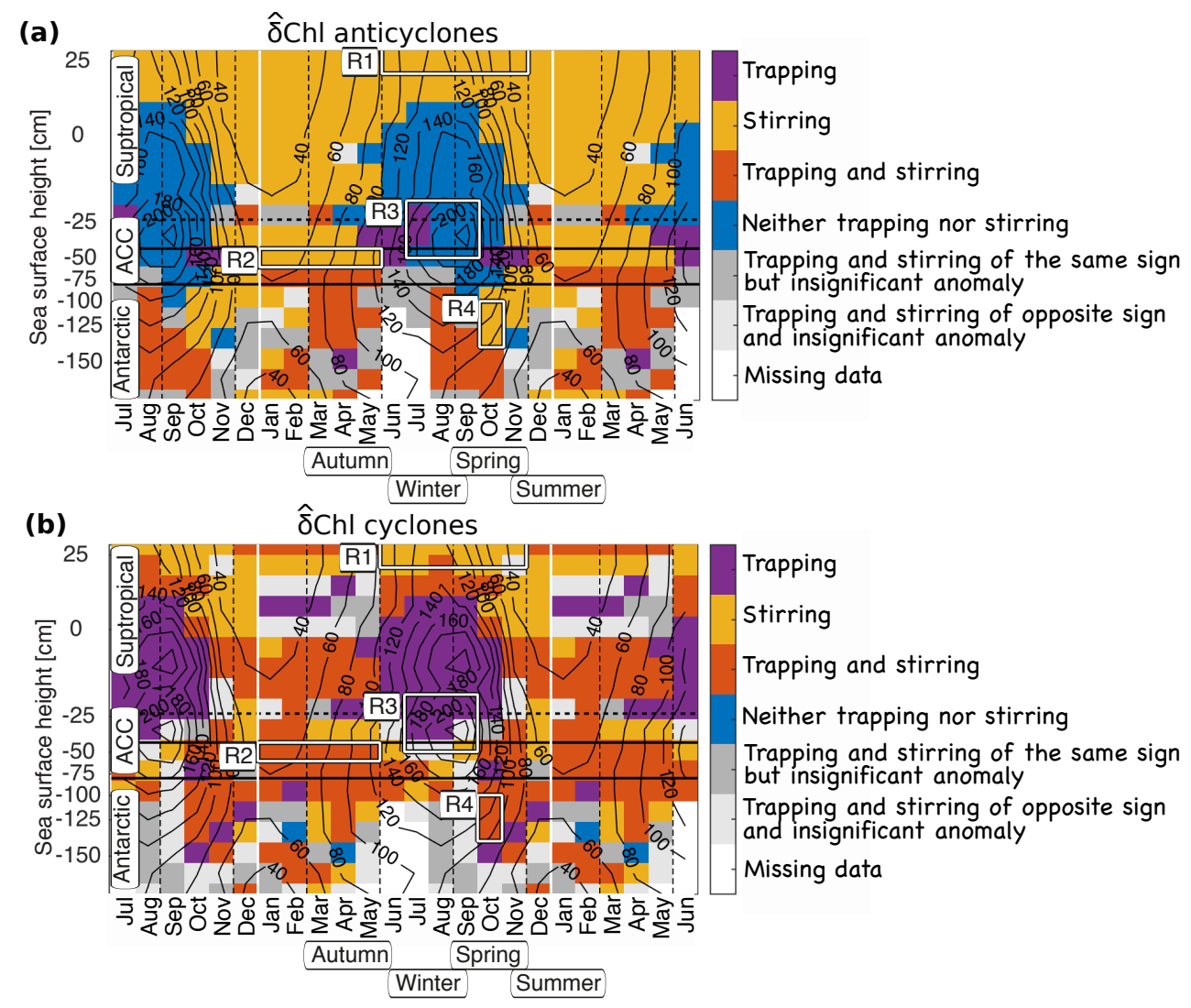

Figure 7. Hovmoeller diagram of the processes likely controlling the chlorophyll anomalies $(\delta \mathrm{Chl})$ in (a) anticyclones and (b) cyclones: trapping (purple), stirring (yellow), a combination of the two (red) or neither of the two (blue), with the latter often interpreted to be the consequence of changes in the local growth or losses (biogeochemical rates). A region is colored if the sign of the potential effect is the same as the observed one, and if $\delta \mathrm{Chl}$ is significant. See text for details. White boxes indicate regions R1 to R4 used for composite Figs. 5 and 6. The data were binned in monthly sea-surface height bins. Horizontal solid black lines mark the ACC, the horizontal dashed black line denotes the $-20 \mathrm{~cm}$ SSH contour, the vertical dashed lines seasons; solid black contours show averaged mixed layer depths in meters; note that the seasonal cycle is shown repeatedly to highlight cyclic patterns.

2013; Guo et al., 2017). Possibly, the underappreciated $\delta \mathrm{Chl}$ along the ACC is due to previous conflation of seasonal anomalies of opposite sign, resulting in a much weaker annual signal. To our knowledge, such seasonal changes in the sign of $\delta \mathrm{Chl}$ in a particular region have not been reported before. Hence, the strong seasonality accompanied by a change in the sign of $\delta \mathrm{Chl}$ along the ACC and south of the ACC appears to be rather specific to the Southern Ocean.

The spatio-temporal variability of $\delta \mathrm{Chl}$ may not be that surprising in hindsight, given that the same mechanism, e.g., advection can lead to either positive or negative signs for the same polarity depending on the sign of the lateral gradient. In addition, several mechanisms may be involved simultaneously, so that small differences in their relative importance can lead to substantial differences in the net sign of the response (Siegel et al., 2011; Gaube et al., 2014; McGillicuddy Jr., 2016). Nevertheless, we have demonstrated that most of the eddy induced signatures of $\delta \mathrm{Chl}$ in the Southern Ocean are likely due to stirring, a mechanism that has been shown to control $\delta \mathrm{Chl}$ in the low to mid-latitude ocean as well (Chelton et al., 2011a). Stirring is an effective mechanism for eddies to cause $\delta \mathrm{Chl}$ as eddy rotation is omnidirectional and thus necessarily perpendicular to the ambient $\mathrm{Chl}$ isolines. This fact, combined with the steep meridional Chl gradients in the Southern Ocean, favor stirring as the driving mechanism for $\delta \mathrm{Chl}$. Stirring in such an environment of meridional $\mathrm{Chl}$ gradients supports $\mathrm{Chl}$ anomalies of a banded, zonal structure, similar in pattern and magnitude to the actual observed $\delta \mathrm{Chl}$, in most regions and seasons. Stirring is also favored compared to trapping by the fact that the majority of the eddies are relatively short lived and also have low translational speeds, such that the average eddy does not get far during its lifetime. This means that the eddy is much more likely to efficiently stir the environmental gradient due to its rotation than to move great distances up or down the gradient.

Next to stirring, our work elucidated also the importance of the other processes, namely trapping and changes in bio- 

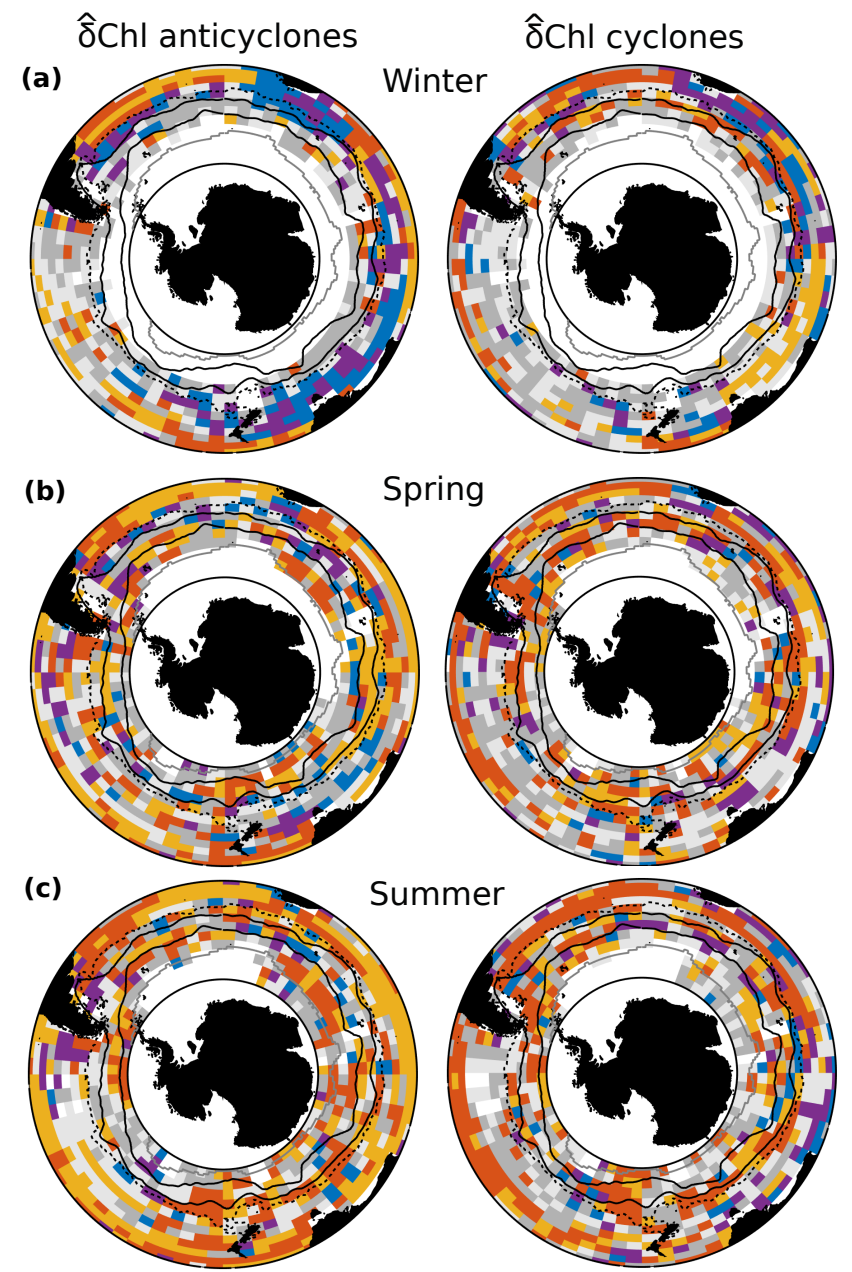

\section{Trapping \\ Stirring \\ Trapping and stirring}

Neither trapping nor stirring

Trapping and stirring of the same sign but insignificant anomaly

Trapping and stirring of opposite sign and insignificant anomaly

- Missing data
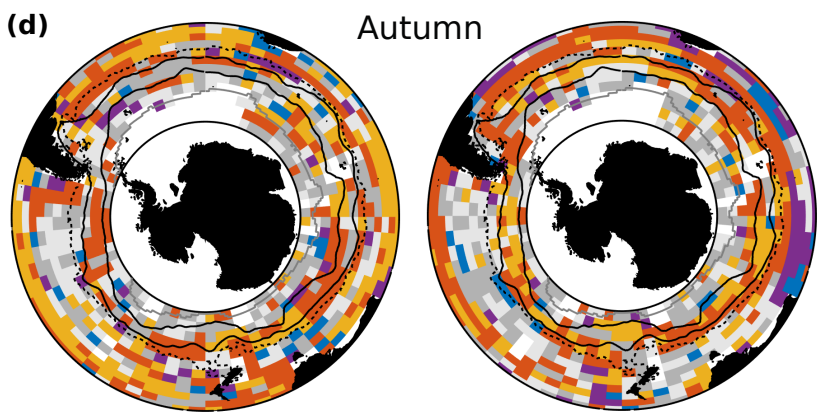

Figure 8. Maps of the distribution of the processes likely controlling the chlorophyll anomalies ( $\delta$ Chl) for austral (a) winter, (b) spring, (c) summer and (d) autumn for anticyclones (left) and cyclones (right). The method and legend is the same as used in Fig. 7. Otherwise the same as Fig. 2.

geochemical rates, in certain regions and at certain times. This leads to a relatively complex mosaic of dominance across space and time in the Southern Ocean (Fig. 7). This synthesis figure reveals that stirring as the sole mechanism is limited to the subtropical waters outside of regions with deep winter mixed layers, and for anticyclones along the northern ACC from summer to autumn (Fig. 7, yellow). Our results suggest that trapping contributes to $\delta \mathrm{Chl}$ for anticyclones along the southern ACC from summer to autumn and in Antarctic waters in autumn and spring. It also adds to the $\delta \mathrm{Chl}$ of cyclones in most regions and seasons, except for parts of the subtropical waters (see also Fig. 8a, south and southwest of Australia). Yet, the magnitude of the potential of trapping is generally small, with the exception, perhaps, of a few specific regions, such as the eastern boundary currents, and those to the southeast of the Kerguelen Islands, and in the Drake Passage (Fig. S3 in the Supplement, see also Gaube et al., 2014). In these regions, eddies tend to move down in- 
tense zonal Chl gradients (Fig. S2 in the Supplement, right column), carrying their high initial $\mathrm{Chl}$ with them. This tends to result in positive $\delta \mathrm{Chl}$ year round for both anticyclones and cyclones (Fig. 3). An additional possible explanation for the positive $\delta \mathrm{Chl}$ is the offshore advection of iron trapped in the nearshore region by eddies that fuels extra growth in the offshore waters, as suggested e.g., for Haida eddies in the North Pacific (Xiu et al., 2011), or for eddies passing the Kerguelen Plateau (d'Ovidio et al., 2015).

The weaker role of trapping relative to stirring can be explained by the inherently westward propagation of mesoscale eddies, meaning a propagation largely along $\mathrm{Chl}$ isolines, as zonal Chl gradients typically are much smaller than meridional Chl gradients. An additional reason is the aforementioned short propagation distance of an average eddy. Moreover, the efficiency of trapping is often also reduced owing to the trapped waters from the eddies' origins being diluted along their pathways (Beron-Vera et al., 2013; Haller, 2015; Wang et al., 2015). This dilution effect may help to explain also the puzzling observation that despite stirring being the dominant process overall, the spatial structure of the $\delta \mathrm{Chl}$ within the eddies is much more monopole than dipole (Figs. 5, 6). This can be resolved by hypothesizing that the lateral entrainment weakens the dipole component of the $\delta \mathrm{Chl}$ generated by stirring, while strengthening the monopole component (see illustration in Fig. 1a).

The clearest case for a substantial contribution of changes in biogeochemical rates on $\delta \mathrm{Chl}$ was found for the northern ACC region during winter and spring, when the mixed layers are deep (Fig. 7, blue), and correlations of Chl and SLA are negative. The associated negative $\delta \mathrm{Chl}$ of anticyclones is consistent with the mechanism of an amplification of the prevailing light limitation in the deep mixed layers (Boyd, 2002; Moore and Abbott, 2002; Venables and Meredith, 2009; Fauchereau et al., 2011). As a result of their suppressing of the thermoclines, anticyclones tend to deepen the mixed layer depths by several tens of meters, especially in winter (Song et al., 2015; Hausmann et al., 2017; Dufois et al., 2016). Hence, phytoplankton within the mixed layer will be exposed to reduced mean light levels in anticyclones as compared to ambient waters, leading to lower phytoplankton growth. The opposite is the case for cyclones.

In the same region from summer to autumn, the weak trapping potential, the pronounced monopole-shape of $\delta \mathrm{Chl}$ and the closed Chl contours suggest that the $\delta \mathrm{Chl}$ is at least partly caused by the effects of eddies on the local biogeochemical rates. Here, the positive correlations of SLA and $\delta \mathrm{Chl}$ could arise due to eddy-induced modifications of the prevailing iron limitation. Anticyclones could reduce the iron limitation and lead to positive $\delta \mathrm{Chl}$ owing to their being more weakly stratified, leading to intensified vertical mixing in the high wind conditions of the Southern Ocean, bringing more iron from below to the surface. Vice-versa, the iron limitation could be enhanced by cyclones owing to their weaker vertical mixing (Dufois et al., 2016; Song et al., 2018). Hy- pothetically, an alleviation of grazing pressure due to reduced predator-prey encounter rates in deepened mixed layers in anticyclones could further favor positive $\delta \mathrm{Chl}$, and more shallow mixed layers could increase grazing pressure for cyclones. Thus, we argue that along the northern ACC, the seasonal sign switch of $\delta \mathrm{Chl}$ could be explained by varying degrees of light and iron limitation and grazing pressure over the course of the year (Smetacek et al., 2004; Carranza and Gille, 2015; Le Quéré et al., 2016).

Finally, along the southern ACC and in Antarctic waters in autumn to spring, the potential of stirring and trapping oftentimes are of the same sign. However, $\delta \mathrm{Chl}$ associated with eddies is insignificant in these waters in many places (dark gray regions, Fig. 7). Presumably, these situations arise because the eddy effects on the local biogeochemical rates may almost perfectly cancel the advective effects.

Our analysis is constrained to the surface ocean, hence three caveats need to be kept in mind: (i) one potential issue is non-homogeneous vertical Chl profiles, e.g., the presence of unrecognized subsurface Chl maxima, but subsurface Chl maxima are presumably not prominent in our focus area (Sallée et al., 2015), as wind speeds are high and mixed layers deep, promoting well-mixed $\mathrm{Chl}$ levels over the upper ocean; further, surface and mixed layer depth integrated analyses provide similar results in terms of SLA-Chl correlations (based on model simulations, Hajoon Song, personal communication, 2017), supporting the assumption that an analysis of surface $\mathrm{Chl}$ is representative for the total $\mathrm{Chl}$ in the water column. (ii) Modification of mixed layer depths by eddies may result in a surface Chl concentration modification due to a dilution effect. Especially in winter to spring, when the mixed layers are deep, we cannot exclude that this effect contributes to the observed $\delta \mathrm{Chl}$. Yet as noted in (i), surface and mixed layer depth integrated analyses provide similar results in a model simulation. (iii) Potential effects of eddies on phytoplankton growth presumably occur mostly in the lower euphotic zone and may thus be expressed more weakly at the surface (McGillicuddy Jr. et al., 2007; Siegel et al., 2011). Therefore, we note that because our study is based on ocean surface data it may underestimate the total effect of mesoscale eddies on biogeochemical rates.

We may further underestimate the overall effect of Southern Ocean eddies on Chl, because of additional effects of mesoscale eddies that are not considered in our analysis. Such effects include the impact of smaller mesoscale features, and of submesoscale processes near the edges of eddies (Woods, 1988; Strass, 1992; Martin et al., 2002; Lévy, 2003; Klein and Lapeyre, 2009; Siegel et al., 2011), e.g., eddy-jet interactions and associated horizontal shear-induced patches of up- and downwelling. Such features are included in our analysis only insofar as they have rectified effects on the larger mesoscale Chl patterns resolved by the data we use. Another effect we do not consider is non-local stirring (d'Ovidio et al., 2015), the contribution of eddies to lateral dispersion outside the eddies' cores in interaction with the 
ambient flow. This effect, for instance, shapes iron plumes downstream of shelves along the ACC, thus preconditioning Chl blooms (Ardyna et al., 2017). Therefore, we note that the overall effect of mesoscale eddies on biogeochemical rates may be larger than suggested by our analysis of the mesoscale, local, imprint of eddies on Chl. Finally, we note that our analysis does not include the effect of submesoscale processes outside eddies as well as any unstructured turbulence in general.

\section{Summary and Conclusions}

The prevalent and strong correlations between anomalies in surface $\mathrm{Chl}$ and mesoscale variability have triggered substantial research, but many unresolved issues remain, particularly regarding their causes (Lévy, 2008; Gaube et al., 2014; McGillicuddy Jr., 2016). With this study, we aim to provide an observational reference for the seasonal climatological $\delta \mathrm{Chl}$ associated with mesoscale eddies across the Southern Ocean, a region where the detailed regional and seasonal relationship of eddies and Chl previously had not been discussed. To this end, we combined satellite estimates of Chl with ocean mesoscale eddies (diameters larger than $\sim 50 \mathrm{~km}$ ) identified based on satellite estimates of SLA. The very large number of collocations of eddies and Chl allowed us to retrieve statistically robust results despite the frequent data gaps and the high spatio-temporal variability of Chl.

We found a relatively complex pattern of $\mathrm{Chl}$ anomalies $(\delta \mathrm{Chl})$ associated with mesoscale eddies, with many anomalies exceeding $\pm 10 \%$ of their mean value over wide areas of the Southern Ocean. The $\delta \mathrm{Chl}$ for cyclones is positive in subtropical waters, but negative along the ACC; anticyclones show a similar pattern, but of opposite sign. A pronounced seasonality of the imprint is apparent especially along the ACC and in Antarctic waters, featuring a sign switch of the anomaly over the course of the year.

While multiple mechanisms may be at play at the same time to cause the observed $\delta \mathrm{Chl}$ (Gaube et al., 2014; McGillicuddy Jr., 2016), our analyses suggest that lateral advection due to stirring by eddies and associated lateral entrainment and permeable trapping explain a large fraction of the observed $\delta \mathrm{Chl}$. This conclusion is based on our analysis of the climatological Chl gradients, eddy rotation and propagation pathways, and the local shape of the $\delta \mathrm{Chl}$ of eddies.

A prominent region and season where eddy-induced advection is insufficient to explain $\delta \mathrm{Chl}$ are the northern ACC characterized by deep mixed layers during winter and spring and a seasonal sign switch of $\delta \mathrm{Chl}$. Here, winter to spring negative and positive $\delta \mathrm{Chl}$ of anticyclones and cyclones, respectively, are consistent with changes in mixed layer depth and the ensuing light regime. The opposite signs of $\delta \mathrm{Chl}$ from summer to autumn are consistent with an abatement of iron limitation by anticyclones via a relatively weak stratification facilitating vertical mixing, and, possibly, with an abatement of grazing pressure caused by anticyclones through deepened mixed layers; and vice versa for cyclones. In other regions and seasons our analysis does not exclude a modulation of $\delta \mathrm{Chl}$ by effects of eddies on biogeochemical rates, even though our results suggest that lateral advection is likely the dominant mechanism.

Future work may include the investigation of where and when Southern Ocean eddies substantially affect biogeochemical rates, such as through modulation of alternating roles of iron and light limitation as well as grazing pressure along the ACC (Song et al., 2018). The growing number of sub-surface biogeochemical measurements across eddies may be of help here, such as those collected by the increasing number of biogeochemical floats (http://biogeochemical-argo.org, last access: 2 August 2018). In addition, targeted experiments with numerical oceanbiogeochemical models with the option to alternately switch on and off $\mathrm{Chl}$ sources and sinks could be employed to shed light on the questions of what the role of eddy-effects is on $\mathrm{Chl}$ sources and sinks relative to advection, for higher trophic levels (Nel et al., 2001; Godø et al., 2012), or for the magnitude and structure of export (Waite et al., 2016). Furthermore, such models could be used to assess if these effects of eddies on phytoplankton substantially affect Southern Ocean biogeochemistry. Of particular interest are their modifications of the mode waters that originate from the Southern Ocean region with deep winter mixed layers. This is crucial, as these mode waters supply the low latitude ocean with nutrients and sequester a substantial amount of anthropogenic carbon (Sarmiento et al., 2004; Sallée et al., 2012). The final thread is the expansion of this work to smaller scales, and perhaps also more ephemeral turbulent structures, such as fronts.

Data availability. The identified eddies we used in this study including their Chl characteristics are publicly available (https://doi. org/10.3929/ethz-b-000238826) (Frenger, 2018). Other presented data are available from the corresponding author upon request.

Supplement. The supplement related to this article is available online at: https://doi.org/10.5194/bg-15-4781-2018-supplement.

Author contributions. IF, NG, and MM conceived the project, IF carried out the analyses, all authors contributed to the writing of the manuscript.

Competing interests. The authors declare that they have no conflict of interest.

Acknowledgements. The altimeter products used for this study were produced by Ssalto/Duacs and distributed by Aviso, with support from Cnes. The Chl used were processed and distributed 
by ACRI-ST GlobColour service, supported by EU FP7 MyOcean \& ESA GlobColour Projects, using ESA ENVISAT MERIS data, NASA MODIS and SeaWiFS data. We thank Francesco d'Ovidio and Volker Strass for their suggestions that improved the paper.

The article processing charges for this open-access

publication were covered by a Research

Centre of the Helmholtz Association.

Edited by: Christine Klaas

Reviewed by: Francesco d'Ovidio and Volker Strass

\section{References}

Abraham, E. R.: The generation of plankton patchiness by turbulent stirring, Nature, 391, 577-580, https://doi.org/10.1038/35361, 1998.

Ansorge, I. J., Pakhomov, E. A., Kaehler, S., Lutjeharms, J. R. E., and Durgadoo, J. V.: Physical and biological coupling in eddies in the lee of the South-West Indian Ridge, Polar Biol., 33, 747759, https://doi.org/10.1007/s00300-009-0752-9, 2010.

Ardyna, M., Claustre, H., Sallée, J. B., D’Ovidio, F., Gentili, B., van Dijken, G., D'Ortenzio, F., and Arrigo, K. R.: Delineating environmental control of phytoplankton biomass and phenology in the Southern Ocean, Geophys. Res. Lett., 44, 5016-5024, https://doi.org/10.1002/2016GL072428, 2017.

Argo: Argo float data and metadata from Global Data Assembly Centre (Argo GDAC), SEANOE, https://doi.org/10.17882/42182, 2000.

Bernard, A., Ansorge, I., Froneman, P., Lutjeharms, J., Bernard, K., and Swart, N.: Entrainment of Antarctic euphausiids across the Antarctic Polar Front by a cold eddy, Deep-Sea Res. Pt. I, 54, 1841-1851, https://doi.org/10.1016/j.dsr.2007.06.007, 2007.

Beron-Vera, F. J., Wang, Y., Olascoaga, M. J., Goni, G. J., and Haller, G.: Objective detection of oceanic eddies and the Agulhas Leakage, J. Phys. Oceanogr., 43, 1426-1438, https://doi.org/10.1175/JPO-D-12-0171.1, 2013.

Boyd, P. W.: Environmental factors controlling phytoplankton processes in the Southern Ocean, J. Phycol., 38, 844-861, https://doi.org/10.1046/j.1529-8817.2002.t01-1-01203.x, 2002.

Boyd, P. W., Arrigo, K. R., Strzepek, R., and van Dijken, G. L.: Mapping phytoplankton iron utilization: Insights into Southern Ocean supply mechanisms, J. Geophys. Res., 117, C06009, https://doi.org/10.1029/2011JC007726, 2012.

Bracco, A., Provenzale, A., and Scheuring, I.: Mesoscale vortices and the paradox of the plankton, P. Roy. Soc. Lond. B. Bio., 267, 1795-1800, https://doi.org/10.1098/rspb.2000.1212, 2000.

Campbell, J. W.: The lognormal distribution as a model for biooptical variability in the sea, J. Geophys. Res., 100, 1323713254, https://doi.org/10.1029/95JC00458, 1995.

Carranza, M. M. and Gille, S. T.: Southern Ocean winddriven entrainment enhances satellite chlorophyll- $a$ through the summer, J. Geophys. Res.-Oceans, 120, 304-323, https://doi.org/10.1002/2014JC010203, 2015.

Chelton, D. B., Gaube, P., Schlax, M. G., Early, J. J., and Samelson, R. M.: The influence of nonlinear mesoscale eddies on near-surface oceanic chlorophyll, Science, 334, 328-332, https://doi.org/10.1126/science.1208897, 2011a.
Chelton, D. B., Schlax, M. G., and Samelson, R. M.: Global observations of nonlinear mesoscale eddies, Prog. Oceanogr., 91, 167-216, https://doi.org/10.1016/j.pocean.2011.01.002, $2011 \mathrm{~b}$.

Comiso, J. C., McClain, C. R., Sullivan, C. W., Ryan, J. P., and Leona, C. L.: Coastal zone color scanner pigment concentrations in the Southern Ocean and relationships to geophysical surface features, J. Geophys. Res., 98, 2419-2451, https://doi.org/10.1029/92JC02505, 1993.

Denman, K. L. and Gargett, A. E.: Biological-physical interactions in the upper ocean: The role of vertical and small scale transport processes, Annu. Rev. Fluid Mech., 27, 225-256, https://doi.org/10.1146/annurev.fl.27.010195.001301, 1995.

Doney, S. C., Glover, D. M., McCue, S. J., and Fuentes, M.: Mesoscale variability of Sea-viewing Wide Field-ofview Sensor (SeaWiFS) satellite ocean color: Global patterns and spatial scales, J. Geophys. Res., 108, 3024, https://doi.org/10.1029/2001JC000843, 2003.

D’Ovidio, F., De Monte, S., Alvain, S., Dandonneau, Y., and Lévy, M.: Fluid dynamical niches of phytoplankton types., P. Natl. Acad. Sci. USA, 107, 18366-18370, https://doi.org/10.1073/1004620107, 2010.

d'Ovidio, F., Della Penna, A., Trull, T. W., Nencioli, F., Pujol, M.-I., Rio, M.-H., Park, Y.-H., Cotté, C., Zhou, M., and Blain, S.: The biogeochemical structuring role of horizontal stirring: Lagrangian perspectives on iron delivery downstream of the Kerguelen Plateau, Biogeosciences, 12, 55675581, https://doi.org/10.5194/bg-12-5567-2015, 2015.

Dufois, F., Hardman-Mountford, N. J., Greenwood, J., Richardson, A. J., Feng, M., and Matear, R. J.: Anticyclonic eddies are more productive than cyclonic eddies in subtropical gyres because of winter mixing, Sci. Adv., 2, e1600282, https://doi.org/10.1126/sciadv.1600282, 2016.

Early, J. J., Samelson, R. M., and Chelton, D. B.: The evolution and propagation of quasigeostrophic ocean eddies, J. Phys. Oceanogr., 41, 1535-1555, https://doi.org/10.1175/2011JPO4601.1, 2011.

Falkowski, P.: Ocean Science: The power of plankton, Nature, 483, 17-20, https://doi.org/10.1038/483S17a, 2012.

Falkowski, P. G., Ziemann, D., Kolber, Z., and Bienfang, P. K.: Role of eddy pumping in enhancing primary production in the ocean, Nature, 352, 55-58, https://doi.org/10.1038/352055a0, 1991.

Fauchereau, N., Tagliabue, A., Bopp, L., and Monteiro, P. M. S.: The response of phytoplankton biomass to transient mixing events in the Southern Ocean, Geophys. Res. Lett., 38, L17601, https://doi.org/10.1029/2011GL048498, 2011.

Field, C. B., Behrenfeld, M. J., Randerson, J. T., and Falkowski, P.: Primary production of the biosphere: Integrating terrestrial and oceanic components, Science, 281, 237-240, https://doi.org/10.1126/SCIENCE.281.5374.237, 1998.

Flierl, G. R.: Particle motions in large-amplitude wave fields, Geophys. Astro. Fluid., 18, 39-74, https://doi.org/10.1080/03091928108208773, 1981.

Frenger, I.: Southern Ocean mesoscale eddies, https://doi.org/10.3929/ethz-b-000238826, 2018.

Frenger, I., Gruber, N., Knutti, R., and Münnich, M.: Imprint of Southern Ocean eddies on winds, clouds and rainfall, Nat. Geosci., 6, 608-612, https://doi.org/10.1038/ngeo1863, 2013. 
Frenger, I., Münnich, M., Gruber, N., and Knutti, R.: Southern Ocean eddy phenomenology, J. Geophys. Res.-Oceans, 120, 7413-7449, https://doi.org/10.1002/2015JC011047, 2015.

Gaube, P., Chelton, D. B., Strutton, P. G., and Behrenfeld, M. J.: Satellite observations of chlorophyll, phytoplankton biomass, and Ekman pumping in nonlinear mesoscale eddies, J. Geophys. Res.-Oceans, 118, 6349-6370, https://doi.org/10.1002/2013JC009027, 2013.

Gaube, P., McGillicuddy Jr., D. J., Chelton, D. B., Behrenfeld, J. B., and Strutton, P. G.: Regional variations in the influence of mesoscale eddies on near-surface chlorophyll, J. Geophys. Res.-Oceans, 119, 8195-8220, https://doi.org/10.1002/2014JC010111, 2014.

Glover, D. M., Doney, S. C., Oestreich, W. K., and Tullo, A. W.: Geostatistical analysis of mesoscale spatial variability and error in SeaWiFS and MODIS/Aqua global ocean color data, J. Geophys. Res.-Oceans, 123, 22-39, https://doi.org/10.1002/2017JC013023, 2018.

Godø, O. R., Samuelsen, A., Macaulay, G. J., Patel, R., Hjøllo, S. S., Horne, J., Kaartvedt, S., and Johannessen, J. A.: Mesoscale eddies are oases for higher trophic marine life, PLoS ONE, 7, e30161, https://doi.org/10.1371/journal.pone.0030161, 2012.

Gower, J. F. R., Denman, K. L., and Holyer, R. J.: Phytoplankton patchiness indicates the fluctuation spectrum of mesoscale oceanic structure, Nature, 288, 157-159, https://doi.org/10.1038/288157a0, 1980.

Gruber, N., Lachkar, Z., Frenzel, H., Marchesiello, P., Münnich, M., McWilliams, J. C., Nagai, T., and Plattner, G.$\mathrm{K}$.: Eddy-induced reduction of biological production in eastern boundary upwelling systems, Nat. Geosci., 4, 787-792, https://doi.org/10.1038/ngeo1273, 2011.

Guo, M., Xiu, P., Li, S., Chai, F., Xue, H., Zhou, K., and Dai, M.: Seasonal variability and mechanisms regulating chlorophyll distribution in mesoscale eddies in the South China Sea, J. Geophys. Res.-Oceans, 122, 5329-5347, https://doi.org/10.1002/2016JC012670, 2017.

Haller, G.: Lagrangian Coherent Structures, Annu. Rev. Fluid Mech., 47, 137-162, https://doi.org/10.1146/annurev-fluid010313-141322, 2015.

Hausmann, U. and Czaja, A.: The observed signature of mesoscale eddies in sea surface temperature and the associated heat transport, Deep-Sea Res. Pt. I, 70, 60-72, https://doi.org/10.1016/j.dsr.2012.08.005, 2012.

Hausmann, U., McGillicuddy Jr., D. J., and Marshall, J.: Observed mesoscale eddy signatures in Southern Ocean surface mixed-layer depth, J. Geophys. Res.-Oceans, 122, 617-635, https://doi.org/10.1002/2016JC012225, 2017.

Kahru, M., Mitchell, B. G., Gille, S. T., Hewes, C. D., and Holm-Hansen, O.: Eddies enhance biological production in the Weddell-Scotia confluence of the Southern Ocean, Geophys. Res. Lett., 34, L14603, https://doi.org/10.1029/2007GL030430, 2007.

Klein, P. and Lapeyre, G.: The oceanic vertical pump induced by mesoscale and submesoscale turbulence, Annu. Rev. Mar. Sci., 1, 351-375, https://doi.org/10.1146/annurev.marine.010908.163704, 2009.

Le Quéré, C., Buitenhuis, E. T., Moriarty, R., Alvain, S., Aumont, O., Bopp, L., Chollet, S., Enright, C., Franklin, D. J., Geider, R. J., Harrison, S. P., Hirst, A. G., Larsen, S., Legendre, L., Platt,
T., Prentice, I. C., Rivkin, R. B., Sailley, S., Sathyendranath, S., Stephens, N., Vogt, M., and Vallina, S. M.: Role of zooplankton dynamics for Southern Ocean phytoplankton biomass and global biogeochemical cycles, Biogeosciences, 13, 4111-4133, https://doi.org/10.5194/bg-13-4111-2016, 2016.

Lehahn, Y., D’Ovidio, F., Lévy, M., Amitai, Y., and Heifetz, E.: Long range transport of a quasi isolated chlorophyll patch by an Agulhas ring, Geophys. Res. Lett., 38, L16610, https://doi.org/10.1029/2011GL048588, 2011.

Lévy, M.: Mesoscale variability of phytoplankton and of new production: Impact of the large-scale nutrient distribution, J. Geophys. Res., 108, 3358, https://doi.org/10.1029/2002JC001577, 2003.

Lévy, M.: The modulation of biological production by oceanic mesoscale turbulence, in: Transport and Mixing in Geophysical Flows. Lecture Notes in Physics, edited by: Weiss, J. B. and Provenzale, A., Springer, Berlin, Heidelberg, Germany, 744, 219-261, https://doi.org/10.1007/978-3-540-75215-8_9, 2008.

Llido, J.: Event-scale blooms drive enhanced primary productivity at the Subtropical Convergence, Geophys. Res. Lett., 32, L15611, https://doi.org/10.1029/2005GL022880, 2005.

Mahadevan, A.: The impact of submesoscale physics on primary productivity of plankton, Annu. Rev. Mar. Sci., 8, 161-184, https://doi.org/10.1146/annurev-marine-010814-015912, 2016.

Mahadevan, A., Thomas, L. N., and Tandon, A.: Comment on "Eddy/wind interactions stimulate extraordinary mid-ocean plankton blooms", Science, 320, 448, https://doi.org/10.1126/science.1152111, 2008.

Mahadevan, A., D'Asaro, E., Lee, C., and Perry, M. J.: Eddy-driven stratification initiates North Atlantic spring phytoplankton blooms, Science, 337, 54-58, https://doi.org/10.1126/science.1218740, 2012.

Maritorena, S. and Siegel, D. A.: Consistent merging of satellite ocean color data sets using a biooptical model, Remote Sens. Environ., 94, 429-440, https://doi.org/10.1016/j.rse.2004.08.014, 2005.

Maritorena, S., D’Andon, O. H. F., Mangin, A., and Siegel, D. A.: Merged satellite ocean color data products using a bio-optical model: Characteristics, benefits and issues, Remote Sens. Environ., 114, 1791-1804, https://doi.org/10.1016/j.rse.2010.04.002, 2010.

Martin, A. P., Richards, K. J., Bracco, A., and Provenzale, A.: Patchy productivity in the open ocean, Global Biogeochem. Cy., 16, 1025, https://doi.org/10.1029/2001GB001449, 2002.

Maximenko, N., Niiler, P., Rio, M.-H., Melnichenko, O., Centurioni, L., Chambers, D., Zlotnicki, V., and Galperin, B.: Mean dynamic topography of the ocean derived from satellite and drifting buoy data using three different techniques, J. Atmos. Ocean. Tech., 26, 1910-1919, https://doi.org/10.1175/2009JTECHO672.1, 2009.

McGillicuddy Jr., D. J.: Mechanisms of physical-biologicalbiogeochemical interaction at the oceanic mesoscale., Annu. Rev. Mar. Sci, 8, 125-159, https://doi.org/10.1146/annurevmarine-010814-015606, 2016.

McGillicuddy Jr., D. J., Anderson, L. A., Bates, N. R., Bibby, T., Buesseler, K. O., Carlson, C. A., Davis, C. S., Ewart, C., Falkowski, P. G., Goldthwait, S. A., Hansell, D. A., Jenkins, W. J., Johnson, R., Kosnyrev, V. K., Ledwell, J. R., Li, Q. P., Siegel, D. A., and Steinberg, D. K.: Eddy/wind interactions stim- 
ulate extraordinary mid-ocean plankton blooms., Science, 316, 1021-1026, https://doi.org/10.1126/science.1136256, 2007.

Moore, J. K. and Abbott, M. R.: Surface chlorophyll concentrations in relation to the Antarctic Polar Front: Seasonal and spatial patterns from satellite observations, J. Marine Syst., 37, 69-86, https://doi.org/10.1016/S0924-7963(02)00196-3, 2002.

Nel, D., Lutjeharms, J., Pakhomov, E., Ansorge, I., Ryan, P., and Klages, N.: Exploitation of mesoscale oceanographic features by grey-headed albatross Thalassarche chrysostoma in the southern Indian Ocean, Mar. Ecol. Prog. Ser., 217, 15-26, https://doi.org/10.3354/meps217015, 2001.

O'Brien, R. C., Cipollini, P., and Blundell, J. R.: Manifestation of oceanic Rossby waves in long-term multiparametric satellite datasets, Remote Sens. Environ., 129, 111-121, https://doi.org/10.1016/j.rse.2012.10.024, 2013.

Oschlies, A.: Can eddies make ocean deserts bloom?, Global Biogeochem. Cy., 16, 1106, https://doi.org/10.1029/2001GB001830, 2002.

Park, K.-A., Cornillon, P., and Codiga, D. L.: Modification of surface winds near ocean fronts: Effects of Gulf Stream rings on scatterometer (QuikSCAT, NSCAT) wind observations, J. Geophys. Res., 111, C03021, https://doi.org/10.1029/2005JC003016, 2006.

Pomeroy, L. R.: The ocean's food web, a changing paradigm, BioScience, 24, 499-504, https://doi.org/10.2307/1296885, 1974.

Sallée, J. B., Speer, K., and Morrow, R.: Response of the Antarctic Circumpolar Current to atmospheric variability, J. Climate, 21, 3020-3039, https://doi.org/10.1175/2007JCLI1702.1, 2008.

Sallée, J.-B., Matear, R. J., Rintoul, S. R., and Lenton, A.: Localized subduction of anthropogenic carbon dioxide in the Southern Hemisphere oceans, Nat. Geosci., 5, 579-584, https://doi.org/10.1038/ngeo1523, 2012.

Sallée, J.-B., Llort, J., Tagliabue, A., and Lévy, M.: Characterization of distinct bloom phenology regimes in the Southern Ocean, ICES J. Mar. Sci., 72, 1985-1998, https://doi.org/10.1093/icesjms/fsv069, 2015.

Sarmiento, J. L. and Gruber, N.: Ocean Biogeochemical Dynamics, Princeton University Press, Princeton, NJ, USA, 526 pp., 2006.

Sarmiento, J. L., Gruber, N., Brzezinski, M. A., and Dunne, J. P.: High-latitude controls of thermocline nutrients and low latitude biological productivity, Nature, 427, 56-60, https://doi.org/10.1038/nature02127, 2004.

Siegel, D. A., Court, D. B., Menzies, D. W., Peterson, P., Maritorena, S., and Nelson, N. B.: Satellite and in situ observations of the bio-optical signatures of two mesoscale eddies in the Sargasso Sea, Deep-Sea Res. Pt. II, 55, 1218-1230, https://doi.org/10.1016/j.dsr2.2008.01.012, 2008.

Siegel, D. A., Peterson, P., McGillicuddy Jr., D. J., Maritorena, S., and Nelson, N. B.: Bio-optical footprints created by mesoscale eddies in the Sargasso Sea, Geophys. Res. Lett., 38, L13608, https://doi.org/10.1029/2011GL047660, 2011.

Small, R., DeSzoeke, S., Xie, S., O’Neill, L., Seo, H., Song, Q., Cornillon, P., Spall, M., and Minobe, S.: Air-sea interaction over ocean fronts and eddies, Dynam. Atmos. Oceans, 45, 274-319, https://doi.org/10.1016/j.dynatmoce.2008.01.001, 2008.

Smetacek, V., Assmy, P., and Henjes, J.: The role of grazing in structuring Southern Ocean pelagic ecosystems and biogeochemical cycles, Antarct. Sci., 16, 541-558, https://doi.org/10.1017/S0954102004002317, 2004.
Sokolov, S. and Rintoul, S. R.: On the relationship between fronts of the Antarctic Circumpolar Current and surface chlorophyll concentrations in the Southern Ocean, J. Geophys. Res., 112, C07030, https://doi.org/10.1029/2006JC004072, 2007.

Song, H., Marshall, J., Gaube, P., and McGillicuddy Jr., D. J.: Anomalous chlorofluorocarbon uptake by mesoscale eddies in the Drake Passage region, J. Geophys. Res.-Oceans, 120, 10651078, https://doi.org/10.1002/2014JC010292, 2015.

Song, H., Long, M. C., Gaube, P., Frenger, I., Marshall, J., and McGillicuddy Jr., D. J.: Seasonal variation in the correlation between anomalies of sea level and chlorophyll in the Antarctic Circumpolar Current, Geophys. Res. Lett., 45, 5011-5019, https://doi.org/10.1029/2017GL076246, 2018.

Stammer, D.: Global characteristics of ocean variability estimated from regional TOPEX/POSEIDON altimeter measurements, J. Phys. Oceanogr., 27, 1743-1769, https://doi.org/10.1175/15200485(1997)027<1743:GCOOVE>2.0.CO;2, 1997.

Strass, V. H.: Chlorophyll patchiness caused by mesoscale upwelling at fronts, Deep-Sea Res., 39, 75-96, https://doi.org/10.1016/0198-0149(92)90021-K, 1992.

Strass, V. H., Naveira Garabato, A. C., Pollard, R. T., Fischer, H. I., Hense, I., Allen, J. T., Read, J. F., Leach, H., and Smetacek, V.: Mesoscale frontal dynamics: shaping the environment of primary production in the Antarctic Circumpolar Current, DeepSea Res. Pt. II, 49, 3735-3769, https://doi.org/10.1016/S09670645(02)00109-1, 2002.

Thomalla, S. J., Fauchereau, N., Swart, S., and Monteiro, P. M. S.: Regional scale characteristics of the seasonal cycle of chlorophyll in the Southern Ocean, Biogeosciences, 8, 2849-2866, https://doi.org/10.5194/bg-8-2849-2011, 2011.

Uz, B. M. and Yoder, J. A.: High frequency and mesoscale variability in SeaWiFS chlorophyll imagery and its relation to other remotely sensed oceanographic variables, Deep-Sea Res. Pt. II, 51, 1001-1017, https://doi.org/10.1016/j.dsr2.2004.03.003, 2004.

Venables, H. J. and Meredith, M. P.: Theory and observations of Ekman flux in the chlorophyll distribution downstream of South Georgia, Geophys. Res. Lett., 36, L23610, https://doi.org/10.1029/2009GL041371, 2009.

Waite, A. M., Stemmann, L., Guidi, L., Calil, P. H. R., Hogg, A. M. C., Feng, M., Thompson, P. A., Picheral, M., and Gorsky, G.: The wineglass effect shapes particle export to the deep ocean in mesoscale eddies, Geophys. Res. Lett., 43, 9791-9800, https://doi.org/10.1002/2015GL066463, 2016.

Wang, Y., Olascoaga, M. J., and Al, W. E. T.: Coherent water transport across the South Atlantic, Geophys. Res. Lett., 42, 40724079, https://doi.org/10.1002/2015GL064089, 2015.

Woods, J.: Scale upwelling and primary production, in: Toward a theory of biological physical interactions in the World Ocean, Springer Netherlands, Dordrecht, the Netherlands, 7-38, https://doi.org/10.1007/978-94-009-3023-0_2, 1988.

Xiu, P., Palacz, A. P., Chai, F., Roy, E. G., and Wells, M. L.: Iron flux induced by Haida eddies in the Gulf of Alaska, Geophys. Res. Lett., 38, L13 607, https://doi.org/10.1029/2011GL047946, 2011. 